\title{
Task specialization and cognitive skills: evidence from PIAAC and IALS
}

\author{
Marta Martínez-Matute $\mathbb{D}^{1} \cdot$ Ernesto Villanueva ${ }^{2}$
}

Received: 16 October 2020 / Accepted: 5 September 2021 / Published online: 23 October 2021

(c) The Author(s) 2021

\begin{abstract}
We study how the tasks conducted on the job relate to measures of cognitive skills using data from 18 countries participating in the Programme for the International Assessment of Adult Competences (PIAAC) and from 13 countries that also participate in the International Adult Literacy Study (IALS). We document two main findings. Firstly, individual-fixed effect models suggest that low-educated workers specializing in a particular set of basic tasks -say, in numeric relative to reading or ICT tasks- obtain $10 \%$ of one standard deviation higher scores in the domain of the PIAAC assessment most related to those tasks than in the rest -say, numeracy relative to literacy or problem-solving scores. Secondly, a synthetic cohort analysis using repeated literacy assessments in IALS and PIAAC indicates that, among the loweducated, long-run increases in the reading task component of jobs correlate positively with increases in cohort-level literacy scores. The results are stronger among low-skilled workers with less working experience or females -i.e., the set of workers who have had less time to sort in the labor market. An interpretation of our findings is that tasks conducted on the job help in building human capital but are imperfect substitutes of formal schooling.
\end{abstract}

JEL Codes $\mathrm{J} 24 \cdot \mathrm{J} 31 \cdot \mathrm{I} 20$

Keywords Human capital $\cdot$ Tasks $\cdot$ Education $\cdot$ Working experience $\cdot$ Cognitive skills

Marta Martínez-Matute

marta.martinezm@uam.es

$\triangle$ Ernesto Villanueva

ernesto.villanueva@bde.es

1 Universidad Autónoma de Madrid and IZA, Calle Francisco Tomas y Valiente 5, 28049 Madrid, Spain

2 Banco de España, Calle Alcala 48, 28014 Madrid, Spain 


\section{Introduction}

Workers obtain skills both in the formal education system and by learning on-thejob. ${ }^{1}$ While there is a substantial literature on how schooling raises cognitive skills and, in turn, wages, much less is known about how skills are formed by learning on the job. ${ }^{2}$ In particular, previous literature has documented a heterogeneity in experience profiles that could be due to search frictions, increased competition for jobs or differences in human capital accumulation -like the task content of jobs.

Our study uses data on actual tasks conducted on the job and on measures of cognitive skills to study the link between tasks and cognitive skills. We rely on measures of cognitive ability of representative samples of the population of 18 countries participating in PIAAC, an OECD-coordinated effort to measure the skills of the population between 16 and 65 years of age. We measure human capital through three cognitive measures in standardized tests: numeracy, literacy and problem-solving skills. The availability of three different measures is important, as it allows us to relate specific tasks to skills while holding constant an individual-fixed effect.

Measures of cognitive skills are an important source of information because of two main reasons. The first is that measures of cognitive abilities are available for representative samples of the population that include the long-term unemployed. ${ }^{3}$ Conceptually this is important, as the accumulation of human capital by low-skilled is an important policy parameter that may be difficult to measure using wages -as that group is more likely to be affected by non-employment -see Charles, Hurst and Notowidigdo (2016). By proxying human capital with measures of cognitive skills, we avoid econometric problems related to modeling labor market participation. Furthermore, the literature has documented that the skill measures we use are indeed related to wages. ${ }^{4}$

Our empirical strategy draws from the literature that estimates education production functions by using multiple measures of skills. In particular, we estimate the

\footnotetext{
${ }^{1}$ See Mincer (1974), Rosen (1972), Ben Porath (1967).

2 See Card (1999), Angrist \& Krueger (1991), Carneiro, Heckman and Vytlacil (2011). For example, it is well known that wages increase with labor market experience, that the monetary return to experience is typically higher for workers with college and it is lower in low-income countries than in high income countries (see Lagakos et al., (2018)). In addition, the monetary return to experience is lower the larger the size of a cohort -see Jeong et al. (2015).

${ }^{3}$ The depreciation of human capital may depend on the duration of non-participation spells and not so much on the level of qualification prior to the period of unemployment. See Jacobson, LaLonde and Sullivan (1993) and related literature. Also it may depend on the age of the worker when facing the unemployment spell. See Arellano-Bover (2020). As PIAAC collects information about the task content of the last job of unemployed respondents, we are able to include those workers in the analysis.

${ }^{4}$ For example, Leuven, Oosterbeek and van Ophem (2004) document that cross-country variation in the net supply of skills -as measured by the International Adult Literacy Survey- correlates negatively with wages, a relationship that is especially strong among low-skilled workers. An interpretation of the finding is that cognitive skills are indeed priced by the labor market. In addition, Hanushek, Schwerdt, Wiederhold and Woessman (2015) also document that numeracy skills are positively associated to wages in the twentythree countries participating in PIAAC. Nevertheless, the use of wages as a sufficient statistic for human capital is not uncontroversial in an international setting, as different institutional settings may break the link between current wages and skills (Blau \& Kahn (1996)).
} 
contribution of on-the-job learning on human capital by exploiting the availability of multiple measures of cognitive skills for the same individual and the fact that jobs vary in their task content. ${ }^{5}$ For example, we estimate the effect of the relative intensity of numeric (relative to reading) tasks on the job on the relative score in numeracy (versus literacy) tests, using a specification that absorbs any individuallevel characteristic that is constant across human capital measures. ${ }^{6}$ We do similar exercises to test if workers in ICT intensive jobs perform better in the problem solving part of the test than on the literacy part.

The above mentioned estimates control for a fixed-effect that is common across all cognitive measures but also captures sorting components. For example, workers may invest in specific skills at the beginning of their working life anticipating higher monetary returns in future jobs (Lazear (2009)). Alternatively, tasks may have an amenity component, and workers may sort into jobs with those tasks according to their preferences. ${ }^{7}$ To get a sense of the magnitude of that sorting component, we use various methods. The first method assumes that very basic tasks like using a calculator or reading emails are unlikely to increase the cognitive skills of workers with high levels of schooling -we provide some evidence on this regard. As a result, any differential performance in numeracy tests relative to literacy or problem-solving tests associated to specialization in basic numeric tasks among college or high-school workers may reflect sorting across jobs, allowing us to assess to what extent our estimates reflect biases due to selection. A second method combines information from the literacy assessments in the 1994 International Adult Literacy Survey (IALS) and in PIAAC as well as information about the reading and numeric component on jobs to construct synthetic life-cycle profiles of reading tasks and literacy scores -see Barrett \& Riddell (2016). We then regress cohort-level changes in literacy scores on the cohort-level changes in the reading content of jobs. ${ }^{8}$

Our results can be summarized as follows. Individuals with compulsory schooling and working in jobs with a relatively higher intensity of basic numeracy tasks perform relatively better in numeracy tests than in literacy or problem solving tests (and viceversa). Namely, respondents with basic schooling who fully specialize in basic numerical tasks on their jobs obtain between $7 \%$ and $10.8 \%$ of one standard deviation higher scores in the numeracy test than in the literacy test. On the other hand, in our preferred sample of individuals with less than 10 years of experience, the association between specialization in numerical tasks and relative performance in the numerical test is much weaker among individuals with a high school or a college degree. The relationship is also stronger among females. We interpret from the

\footnotetext{
5 We do not model the role of non-cognitive skills - Cunha \& Heckman (2007). However, we control in the analysis below for related variables, like the respondent's assessment about his or her own interest in learning about new things.

${ }^{6}$ In a different, but related setting Silva, Lavy and Weinhardt (2012), Bietenbeck (2014) or Mincer (1974) exploit the availability of multiple measures of cognitive skills and differential exposure across subjects to estimate the impact of peers or teacher characteristics on on test scores.

7 See Lise \& Postel-Vinay (2020), who estimate a model on longitudinal data where workers are endowed with bundles of skills that have different returns depending on job requirements. Sorting across jobs plays an important role in accounting for lifetime output of a worker.

8 That specification holds constant the unobserved initial stock of literacy at the cohort level, and identifies the impact of job content on literacy skills using an alternative set of assumptions from those in the worker fixed-effect model.
} 
methods outlined above that sorting, despite of being an important mechanism on its own, is unlikely to drive all of our results. ${ }^{9}$

An interpretation of our findings is that on-the-job learning by conducting basic numerical, reading or ICT tasks is an imperfect substitute for formal education for workers with compulsory schooling. We draw on evidence in previous studies to obtain a tentative estimate of the degree of substitution between of one year of formal education and between two and four years of skill acquisition on the job. The rest of the paper is organized as follows. Section 2 describes the empirical method. Section 3 describes the datasets. Section 4 discusses the link between between tasks on-the-job and numeracy and literacy scores and the main results. Section 5 presents the main conclusions.

\section{Empirical methods}

We assume that human capital $C_{i}$ is acquired by an individual $i$ through the formal education system (that we denote as $S_{i}$ ) and by the task-content of his or her job, denoted by $J_{i}$. Individuals may also vary in their initial endowment of human capital, $C_{0, i}$, a measure that summarizes factors related to the innate ability of a worker.

$$
C_{i}=\alpha_{0}+\alpha_{1} S_{i}+\alpha_{2} J_{i}+\alpha_{3} J_{i} * S_{i}+C_{0, i}+\epsilon_{i}
$$

We use three different proxies of human capital, $C_{i}$, measured through numeracy, literacy and problem-solving scores in standardized tests $\left(C_{n, i}, C_{l, i}\right.$ and $C_{p, i}$ respectively) and three different measures of tasks performed on each respondent's current or last job: ICT-related $\left(J_{i}=p_{i}\right)$ reading-related $\left(J_{i}=l_{i}\right)$, numeracy-related $\left(J_{i}=n_{i}\right)$. That means that we observe:

$$
C_{m, i}=\alpha_{0, m}+\alpha_{1, m} S_{i}+\alpha_{2, m} J_{i}+\alpha_{3, m} J_{i} * S_{i}+C_{0, i}+\epsilon_{m i}, m=n, l, p
$$

where $C_{0, i}$ absorbs initial skills that affect equally all sorts of cognitive skills (problemsolving, reading or numeracy-related). Also, as PIAAC is a cross-section, note that $C_{0, i}$ is effectively a worker-time fixed effect. For that reason, $C_{0, i}$ also absorbs any characteristic of the employer-employee match (like possible mismatches between the employee qualifications and those required by the job) or, in the case of non-employed individuals, ${ }^{10}$ any depreciation of their human capital that is constant across all cognitive measures. $\epsilon_{m i}$ is a mean-zero unobserved factor reflecting the initial endowment of domain-specific human capital, uncorrelated with the initial amount of general human capital $C_{0, i}{ }^{11}$

\footnotetext{
${ }^{9}$ One important caveat about our estimations is that we do not explicitly account for the endogeneity of the decision to get schooling. However, we note that the correlation between specialization in basic numerical tasks and relative score in the numeracy test is similar across respondents with high school and with a college degree, a fact that suggests that biases due to endogeneity of schooling may not be that large.

${ }^{10}$ See Edin \& Gustavsson (2008) for a detailed analysis on skill depreciation between work interruptions.

11 Model (2) deals with numeracy, literacy and problem solving scores linearly, while many analysts consider thresholds in scores that signal discontinuous changes in respondents skill levels. At this stage, we do not do much about this problem for two reasons. The first is that we rely on worker-level fixed effects, which are hard to incorporate into non-linear models. The second reason is that, as discussed below, one key assumption is that the impact of literacy tasks on literacy scores is similar to the impact of numeric (ICT) tasks on numeracy (problem solving) scores. That assumption is hard to implement in non-linear settings.
} 
We focus on $\alpha_{2, m}$, the impact of domain-specific tasks done on the job (reading, numeric and ICT) on domain-specific cognitive skills $C_{m, i}{ }^{12}$

\subsection{On the job learning vs sorting on the job}

A problem when estimating model (2) is that the failure to hold pre-labour market ability constant, $C_{0, i}$, is likely to result in an upward bias of OLS estimates of $\alpha_{2, m}$ in Model (2). ${ }^{13}$ We exploit multiple measures of human capital for the same individual to control for $C_{0, i}$. In particular, under the assumption that the impact of conducting reading tasks on literacy scores equals the impact of mathematical tasks on numeracy scores (i.e. $\alpha_{2, n}=\alpha_{2, l}=\alpha_{2, p}$ and that $\alpha_{3, n}=\alpha_{3, l}=\alpha_{3, p}$ ), one can take the difference between any pair of skills (say, numeracy vs literacy):

$$
C_{n}-C_{l}=\left[\alpha_{0, n}-\alpha_{0, l}\right]+\left[\alpha_{1, n}-\alpha_{1, l}\right] S+\alpha_{2}[n-l]+\alpha_{3}[n-l] * S+\epsilon_{n}-\epsilon_{l}
$$

Model (3) identifies the impact of tasks performed on-the-job on particular forms of human capital (numeracy vs literacy) by comparing individuals who have different degrees of specialization in the tasks they perform in their jobs (in the example, numeric vs reading tasks, or $n-l$, but we can also estimate the impact on cognitive skills of $n-p$ and $l-p){ }^{14}$

A second consideration in Model (2) is that workers sort in the labour market according to their initial endowment of domain-specific human capital. For example, workers with an initial ability for numeracy-related jobs may sort into numeracyintensive jobs. Alternatively, workers may decide to invest in a set of skills at the beginning of their careers in anticipation of obtaining a better job in the future if the current match dissolves (Lazear (2009)). In other words, workers with a higher value of $\epsilon_{n}-\epsilon_{l}$ (or a comparative advantage in numeracy tasks) are likely to sort into a relatively math-intensive work environment -i.e., with a higher level of $[n-l]$. Sorting would generate a positive correlation between the numeracy content of a job and initial endowment of numerical human capital.

One way to see this bias is a model along the lines of Roy (1951). Assume that jobs are bundles of monetary and non-monetary aspects, the latter being related to the type of tasks they involve (either numeracy or reading- related tasks). ${ }^{15}$ Assuming

\footnotetext{
${ }^{12}$ We gauge the skill gain of workers with basic schooling by examining how the task content of their job (either $p, l$ or $n$ ) correlates with different measures of skills. Ideally, we would like to disentangle between the impact of current tasks on the job and the cumulative impact of tasks in previous jobs -i.e., for the whole history of numeracy or literacy tasks performed in different jobs. However, we deal with repeated cross sections and that information is not available. Hence, when we use as the regressor of interest the type of tasks performed on the job, we also control for the number of years of potential working experience.

13 A possible reason is sorting on general ability if firms retain better workers. Arellano-Bover (2020) documents lower cognitive scores among workers who started their careers at times of higher levels of unemployment, possibly due to starting matches with smaller, worse firms. That could be a reason for an upward bias in the estimation of $\alpha_{2, m}$ in models without individual fixed effects.

14 In particular, an individual fixed-effect model absorbs cohort-level changes in the general ability of workers. See Green \& Riddell (2013) for a discussion in the context of parsing out life-cycle and cohort effects in skill accumulation.

15 Villanueva (2007) shows that workers are willing to sacrifice up to $6 \%$ of their wage to work in a job requiring skills that suit their abilities, suggesting that the skill content of a job may enter their utility function.
} 
that jobs involve either numeric tasks ( $n=1$, as we show below, a salesperson) or reading tasks ( $n=0$, as we discuss below, a personal care worker), conditional on choosing a numeric job, the gap in cognitive skills in math and, say, numeracy can be written as the sum of the return to skills and a selection term:

$$
E\left(C_{n}-C_{l} \mid n=1\right)=\alpha_{2} n+E\left\{\epsilon_{n}-\epsilon_{l} \mid \epsilon_{n}-\epsilon_{l}>k\right\}
$$

That is, the gap between measured numeracy and literacy skills may arise either because workers acquire numeracy skills in their jobs by performing relatively more numeric tasks $\left(\alpha_{2}\right)$ or because of a sorting process that arises both from initial comparative advantage in numeracy skills and for taste for jobs that involve numeracy tasks. While separating the sorting and the productivity components is very difficult we can obtain estimates of $\alpha_{2}$ among groups of workers for whom $(a)$ the ability to sort is limited and $(b)$ the ability to learn from a certain tasks is higher than the rest. If $\alpha_{2}$ is highest among such groups, we can infer that sorting does not account for the relationship between task specialization and human capital accumulation $^{16,17}$

For example consider the case of workers with a college degree, who are arguably more mobile than workers with basic schooling (see Charles et al. (2016)). ${ }^{18}$ Those workers may end up with higher numeracy skill levels -relative to literacy or problem-solving ones- due to their initial endowment of numeracy or because their choice of electives. ${ }^{19}$ Within that group of workers with a college degree, simple numeric tasks like using a calculator are unlikely to increase their skills but they may still be statistically associated to gaps between the numeracy and literacy or problemsolving skills because of sorting. Hence, the correlation between the numeracy vs reading or problem solving scores and the presence of simple numeracy tasks for those workers may simply capture preferences towards jobs with numeracy content.

Our strategy proceeds as follows. We first estimate for basic school workers a regression of the difference between the (normalized) numeracy vs literacy score on the presence of simple numeric tasks -relative to reading or ICT tasks. That estimate measures the causal impact of performing numeric tasks on the normalized numeracy score plus a sorting component. The second step is to estimate the same regression for a sample of individuals with either a high school or a college degree, with a

\footnotetext{
16 See Lise \& Postel-Vinay (2020) on the wage dynamics implied by the match between skills of a worker and job requirements.

17 The expression (4) can be obtained assuming that there is a market return to ability, above and beyond schooling or other covariates $w_{n}=w C_{n}$ where $C_{n}$ is the numeric ability of the worker and $w$ is the market price of the unit of skill, be it numeric or reading-related. Sorting implies that workers choose the numeracy-intensive job if $u\left(w_{n}, n\right)>u\left(w_{l}, 0\right)$ or $C_{n}-C_{l}>\frac{v[0]-v[n]}{w}$ In other words, a worker will choose a numeracy job when the wage return to her numerical ability -relative to the literacy one- exceeds any possible utility loss from conducting numeric, rather than literacy tasks. Further using Model (2), together with $C_{n}=\alpha_{2} n+\epsilon_{n}$ and $C_{l}=\epsilon_{l}$ one can obtain expression (3) in the text.

${ }^{18}$ Low skilled individuals tend to concentrate in particular occupations. As it is shown in Table 7, the six most important occupations account for $45 \%$ of low skilled employment, whereas in the case of high skilled individuals, six main occupations correspond to a $38 \%$ of employment. We interpret from this evidence that low educated individuals have less occupations to sort in as their abilities are concentrated in a specific set of tasks.

${ }^{19}$ We assume that for workers with high education levels, performing simple tasks on their jobs does not lead to an increase in their numerical score, i.e., for those tasks $\alpha_{2}$ equals zero.
} 
higher ability to sort. If $\alpha_{2}$ is largest among workers with basic schooling than among the rest, we infer that the link between tasks and human capital captures learning on the job. We repeat those exercises for numeracy vs problem-solving skills (by comparing scores in numeric jobs vs ICT intensive ones) and literacy vs ICT. ${ }^{20}$

In addition, we use an alternative method to control for initial human capital endowments is to use repeated measures of cognitive abilities over time. For example, using several realizations for the same individual, we could control for $C_{0, i}$ by taking differences over time. Unfortunately, repeated observations on cognitive skills are not available at the individual-level. Nevertheless, the repeated countryspecific assessments in IALS (1994) and PIAAC (2012) make it possible to track cohort-level changes in the evolution of literacy skills and the task content of jobs over the life-cycle in thirteen countries. In particular, taking cohort-specific averages in Model (3):

$$
\bar{C}_{l, c, t}=\alpha_{0, l, t}+\alpha_{l} \bar{J}_{l, c, t}+\bar{C}_{0, c}+\bar{\epsilon}_{l, c}
$$

A hat over a variable denotes its cohort-specific mean (i.e., $\bar{C}_{l, c, t}=\sum_{i} \frac{C_{l, i, t}}{N_{c}}$ is the cohort-specific average of the literacy score and $\bar{J}_{l, c, t}=\sum_{i} \frac{J_{l, i, t}}{N_{c}}$ the cohort-level mean of tasks). We define cohorts as groups of respondents sharing (10-year) date-of birth, country, education level and gender. Drawing on multiple observations for the same cohort over time, one can take within-group differences and estimate $\alpha_{(2, l)}$ as follows:

$$
\bar{C}_{l, c, 2012}-\bar{C}_{l, c, 1994}=\Delta \alpha_{0}+\alpha_{l}\left[\bar{J}_{l, c, 2012}-\bar{J}_{l, c, 1994}\right]+\bar{\epsilon}_{l, c, 2012}-\bar{\epsilon}_{l, c, 1994}
$$

$\bar{J}_{l, c, 2012}-\bar{J}_{l, c, 1994}$ reflects changes in the reading requirements of jobs over time. Unlike Model 2, changes in $\bar{J}_{l, c, 2012}-\bar{J}_{l, c, 1994}$ are unlikely to reflect sorting of individuals across jobs, as it is unlikely that members of a cohort systematically look for the same type of jobs. Still, to test for the presence of sorting due to correlation between $\bar{\epsilon}_{l, c, 2012}-\bar{\epsilon}_{l, c, 1994}$ and $\bar{J}_{l, c, 2012}-\bar{J}_{l, c, 1994}$ we control for changes in numeracy requirements of tasks on the job measured both in IALS (1994) and in PIAAC (2012). Under the assumption that $\alpha_{l}$ mainly picks up the reading content of jobs, it should not be affected by whether or not we introduce other indicators of the task contents of jobs, such as the numeracy intensity. Thus we run an alternative model and test if the numeracy content of jobs explains the increase in literacy. In addition, the initial use of tasks by a cohort could be an indicator of future cognitive skills (through learning) and sorting (if a cohort faces exceptionally low use of a skill, by convergence its use may increase). To verify the extent to which initial conditions are driving our results we introduce controls for the mean reading task use in 1994.

\footnotetext{
${ }^{20}$ Finally, we are taking schooling as exogenous. It is not clear whether the endogeneity of schooling is related to the differential task content of jobs. To informally assess if the endogeneity of schooling affects our estimates, we examine the correlation between performing simple tasks on the job and the difference between numeracy vs literacy scores at various levels of education. To the extent that the correlation does not vary across education groups, other than workers with basic schooling, it gives us confidence that endogeneity of schooling is not affecting our estimates.
} 


\section{Database}

The main data source is the Programme for the International Assessment of Adult Competencies (PIAAC), provided by the OECD and collected between August 2011 and March 2012. PIAAC includes an internationally comparable data on literacy and numeracy proficiency, as well as on the tasks performed at work by adults aged 16-65. We use 18 countries: Belgium, Canada, Czech Republic, Denmark, Estonia, Finland, France, Germany, Ireland, Italy, Korea, Netherlands, Norway, Slovak Republic, Spain, Sweden, USA and the United Kingdom (namely, England and Northern Ireland). ${ }^{21}$

In each country a representative sample of adults between 16 and 65 years took a direct assessment of their proficiency in numeracy, literacy and problem-solving. Numeracy measures the ability of "managing a situation or solving a problem in a real context by responding to mathematical information and content represented in multiple ways". The "literacy" assessment excludes the ability to write, but goes beyond reading ability by measuring "the range of cognitive strategies (...) that adults must bring into play to respond appropriately to a variety of texts of different formats". ${ }^{22}$ The "problem solving" assessment measures the ability of individuals to solve problems that arise using ICTs (...), where problems are a consequence of the availability of new technologies (...) and require the use of computer-based artifacts (...)". Of the countries surveyed, France, Italy and Spain did not include that assessment, so we omit those countries in any model including problem-solving scores (but not in the rest). The survey was implemented either by computer or on paper and pencil. ${ }^{23}$

In addition, PIAAC contains internationally comparable information about the educational attainment of individuals as well as about the tasks performed in the current or last job.

Tasks. The survey asks each employed respondent about how many times he or she conducted a particular task during the last month. In addition, non-employed respondents with previous labour market experience are also asked about the tasks done in their last job. The number of tasks listed in the survey is large, and we have classified them as either numeracy, reading or ICT related. Numeracy-related tasks include elaborating a budget, using a calculator, reading bills, using fractions or percentages, reading diagrams, elaborating graphs or using algebra. We classify as literacy-related tasks reading email, reading guides, reading manuals, writing emails, writing reports, reading articles, reading academic journals, reading books and writing articles. Finally, ICT tasks involve using email, using internet, processing texts, conducting transactions over internet, programming and using spreadsheets.

\footnotetext{
${ }^{21}$ We do not use data on Russia as the data is not really comparable to the rest (see OECD (2013)). The questionnaires in Japan and Poland did not ask about the tasks workers do at their job, so they lack essential data for the analysis.

22 All excerpts from OECD (2013). The exact definition of literacy is understanding, evaluating, using and engaging with written texts to participate in society, to achieve one's goals, and to develop one's knowledge and potential". Numeracy is defined as "the ability to access, use, interpret and communicate mathematical information and ideas, in order to engage in and manage the mathematical demands of a range of situations in adult life".

23 We control for a dummy that indicates whether the individuals conducted the exam on paper.
} 
We also distinguish between basic and advanced tasks using principal component analysis, as their impact on human capital accumulation is likely to vary across educational groups. Regarding numerical tasks, we classify tasks into advanced and basic, and identified elaborating a budget, using a calculator, reading bills, using fractions or percentages and reading diagrams as basic tasks. Conversely, we classify elaborating graphs or using algebra as advanced tasks. ${ }^{24}$ Similarly, we classified reading email, reading guides, reading manuals, writing emails, writing reports and reading articles as simple literacy tasks, while reading academic journals, reading books and writing articles were classified as advanced literacy tasks. Regarding ICT tasks, we classify using email, using internet and conducting transactions over internet as basic, and programming, processing texts and using spreadsheets as advanced tasks. ${ }^{25}$

We measure the numeric task intensity of a job computing the number of math related tasks reported. If a worker reports performing all basic numeric tasks on her job (i.e. if at least once a month she elaborates a budget, reads bills, reads a diagram, uses a calculator, and computes a fraction or percentage in her current or last job) we grant her $1(=5 / 5)$ in "Basic math tasks". If she conducts only one of the five tasks, we grant her $0.20=(1 / 5){ }^{26}$ For example, around $15 \%$ of low educated workers in the overall sample are granted one. We define "Basic literacy tasks" and "Basic ICT tasks" in a similar fashion. The degree of specialization is defined as the difference between "Basic math tasks", "Basic literacy tasks" or "Basic ICT tasks". The resulting distribution of numeracy, literacy and ICT content across 2-digit occupations is shown for individuals with basic schooling in Table 7. Note that the OECD also provides a measure of task intensity, which we introduce alternatively in results of Table $3 .^{27}$ However, the reason why we use our own measure is that to be able to get a scope of the relative magnitude of sorting and on-thejob learning components we draw on the distinction between basic and advanced tasks. The available measure in PIAAC does not allow for that distinction. ${ }^{28,29}$

\footnotetext{
${ }^{24}$ Principal Component Analysis helps us in identifying to what extent those tasks vary jointly across jobs. We do not use the factors resulting from Principal Component Analysis in our exercise except that for the case that it helps us in identifying to what extent those tasks vary jointly across jobs. Regarding numeracy, two main factors account for about $70 \%$ of the total variance. The first factor put equal weights on all tasks, while the second factor weighted only the last two (elaborating diagrams and using algebra). Those results led us into classifying elaborating diagrams and using algebra as advanced tasks, while we consider the rest as basic tasks.

25 Following the same strategy as with numeracy, the first factor put equal weights on all tasks while the second factor weighted only the advanced mentioned, letting us classify them into advanced literacy or ICT tasks. These two factors explain around a $60 \%$ (in the case of literacy) and $70 \%$ (in the case of ICT) of total variance.
}

${ }^{26}$ We interpret that individuals with missing information in these variables do not perform any task.

27 We use the OECD alternative measure of task intensity as a robustness check of our main results in Table 2 due to a couple of reasons. On one hand, the OECD measure of task intensity permits to consider the intensity of doing tasks (not only how many types of tasks the worker conducts). On the other, OECD measure is available for all the individuals in the sample, even those who do not respond to a question related to a specific task performed (a case in which we assume that the worker does not conduct that task. These two concerns might slightly affect our results as an upward bias of our own measure. The OECD skill use measure is not sensitive to these concerns.

${ }^{28}$ Furthermore, the measure is missing for a large part of the sample, resulting in smaller sample sizes than those shown below.

${ }^{29}$ We experiment with other alternative measures of task intensity in the working paper version of the study. 
Formal education. We group individuals in three schooling levels, following a classification elaborated by the OECD. The first is primary education or less. The second is composed of individuals having completed either baccalaureate studies or forms of Vocational Training that, according to the ISCED classification, do not constitute university education. The third group is composed of individuals with any type of university education, including those forms of Vocational Training that ISCED considers equivalent to college.

Sample selection. To obtain a large sample of individuals from different countries we pool employed and unemployed individuals as well as females and males between 16 and 55 years of age. We decided to stop at 55 because at that age the fraction of retired workers jumps to $30 \%$. As there is evidence pointing at retirement as being associated to a sharp cognitive decline and we focus on workers in the labor force, we chose that age range. Finally, we exclude from the sample respondents without labour market experience. The resulting sample contains 83,811 individuals in those 18 countries. Sample sizes per country vary between 19,566 in Canada and 2,737 in Sweden.

\subsection{Summary statistics in PIAAC}

Table 1 shows summary statistics for the 18 countries that conducted the numeric and literacy scores. The fraction of prime workers with basic schooling is $19 \%$ in the full sample, being highest in Spain (43\%) and lowest in the Czech Republic (6\%). The average number of years worked does not change much across countries, in contrast.

Figure 1 shows the fraction of individuals who report having performed in their current or last job one of the basic tasks, by schooling group. Figure $1 \mathrm{~b}$ replicates Fig. 1 by schooling group but for advanced tasks. As expected, the fraction of individuals who report having performed a basic task is larger among those with basic schooling than among those with college. Excluding Finland, Czech and Slovak Republic, between one quarter and one third of individuals with basic schooling perform at least one of the simplest numeric (reading) tasks. That similarity may be surprising, given the large cross-country differences in the fraction of individuals with basic schooling or in the industrial composition. ${ }^{30}$ Thus, the statistics in Figure 1 suggest that, in most of the countries we consider, a nontrivial share of individuals with basic schooling perform simple tasks at their jobs, thus having at least the possibility of acquiring some skills. ${ }^{31}$

\subsection{Evidence from the International Adult Literacy Survey (IALS)}

To implement the synthetic cohort analysis, we combine information from two assessments on Literacy: the 1994 International Adult Literacy Survey (IALS) and

\footnotetext{
${ }^{30}$ The variation in the fraction of respondents with college degree who report having performed advanced tasks is much higher. More than $70 \%$ of graduates in the Czech and Slovak Republics or in Norway, Sweden, Netherlands or Estonia conduct at least one advanced task in their job while the same fraction is around $60 \%$ in Spain, Ireland or Italy (not shown).

${ }^{31}$ The fraction of individuals with primary schooling who perform advanced tasks are really rare, as we can see in Figure $1 b$. 


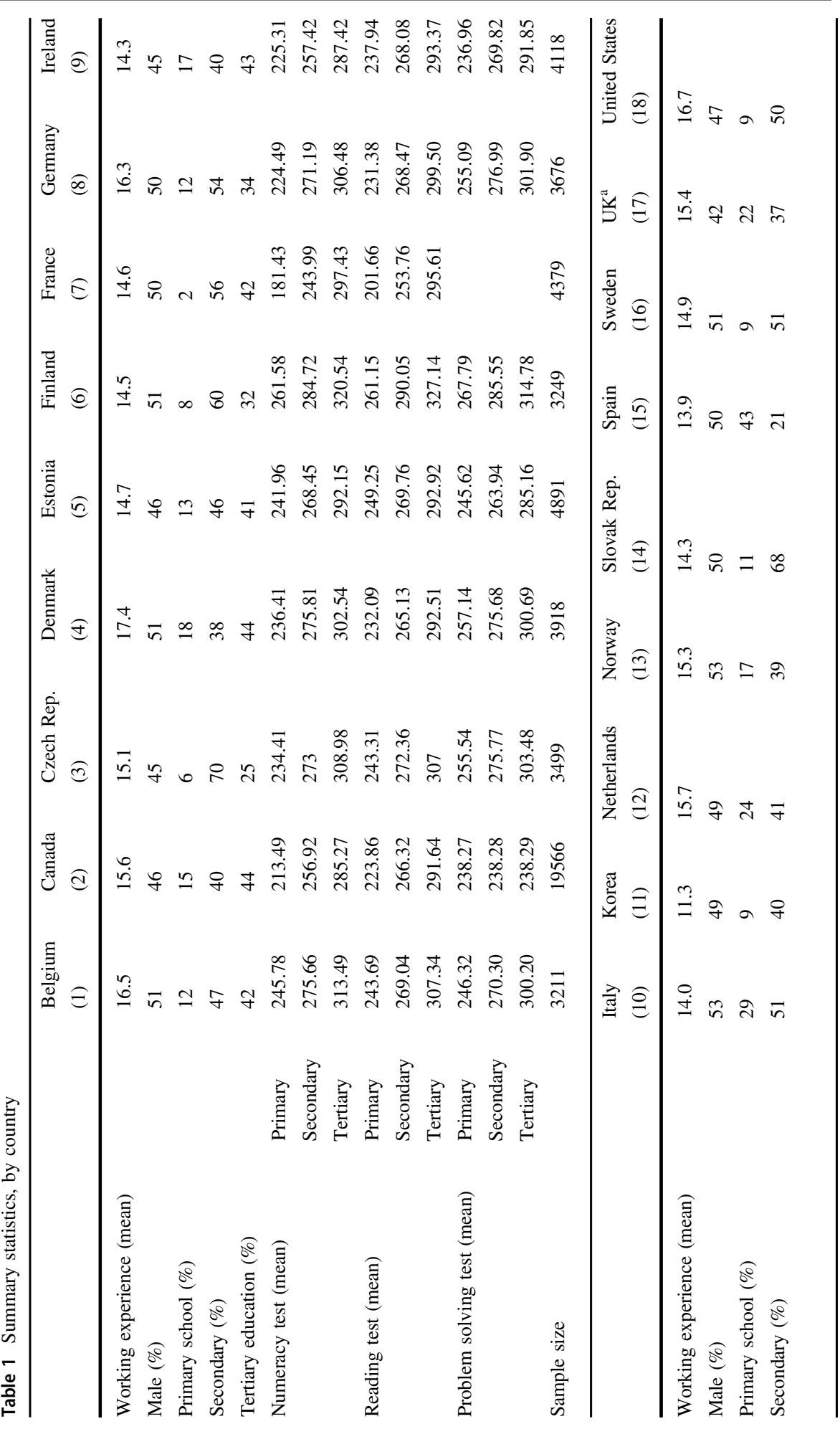




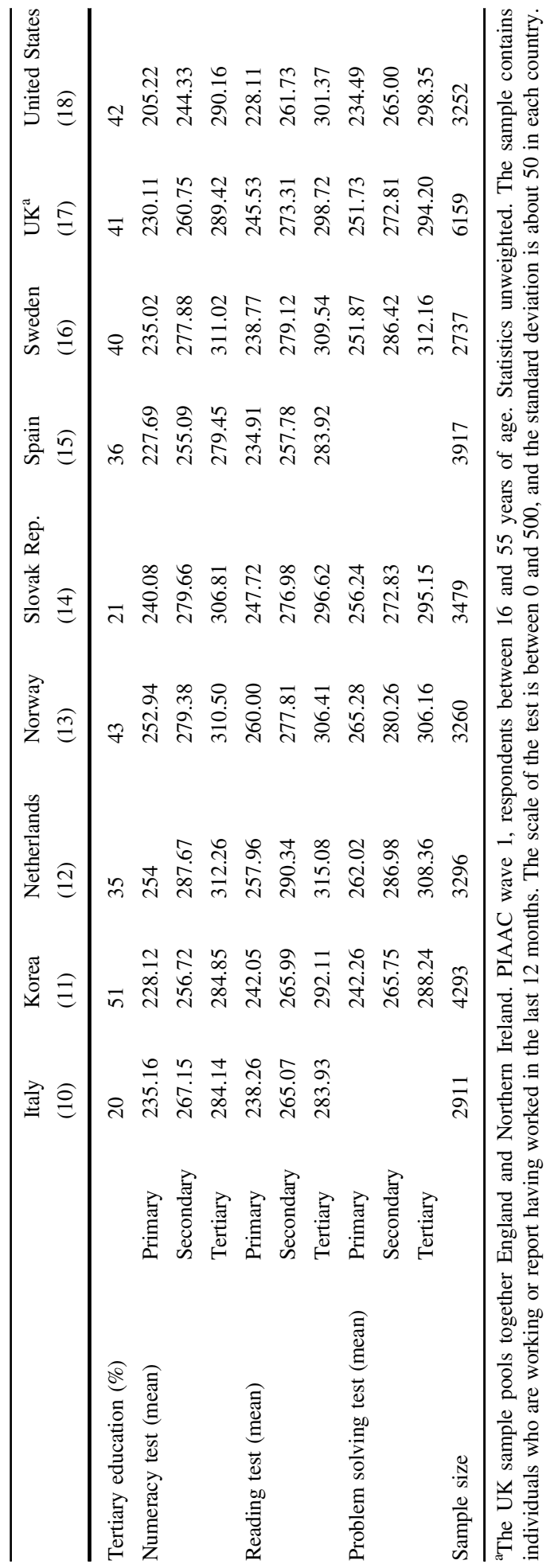



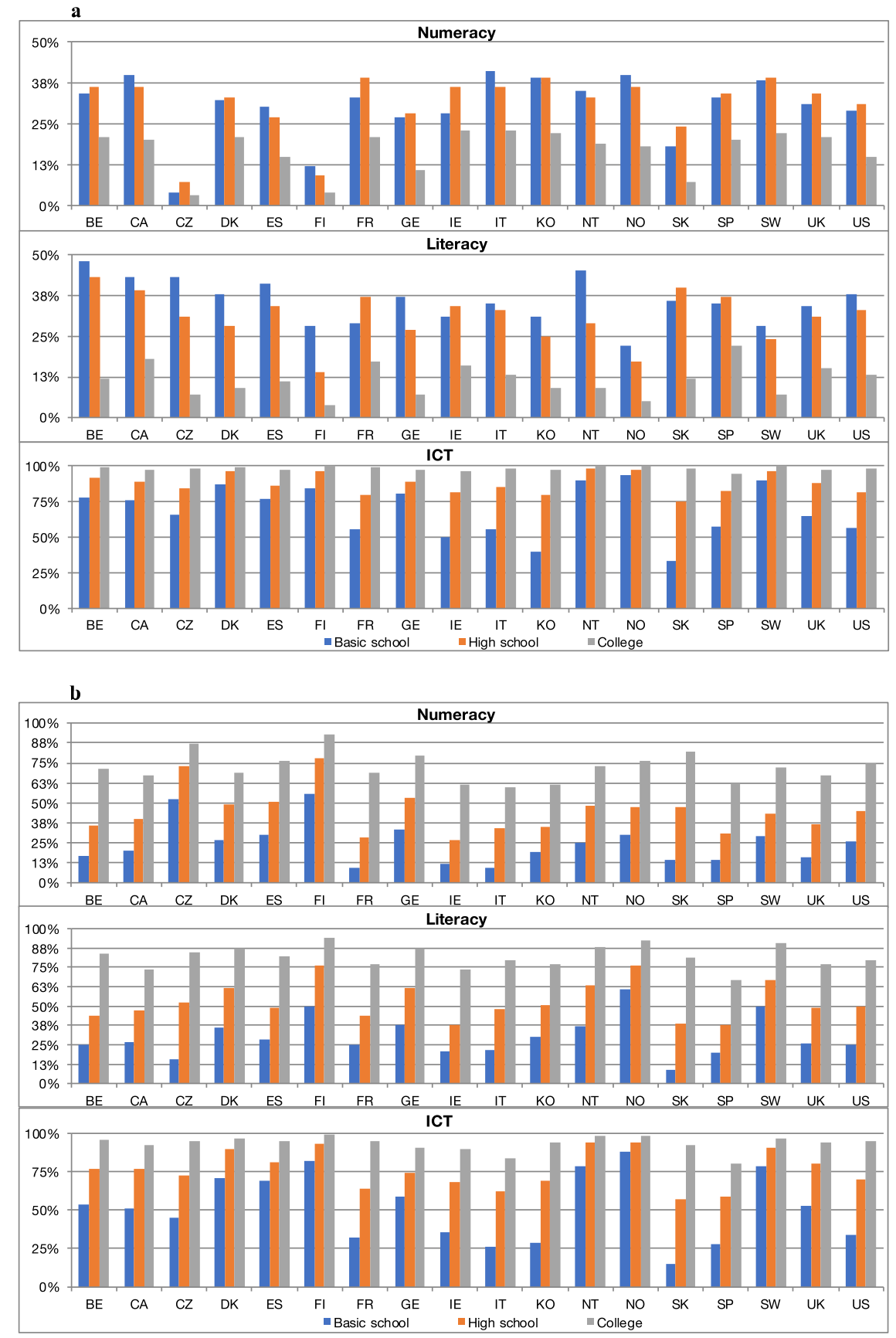
Fig. 1 a Percentage of individuals performing advanced tasks by country and level of education. Source: PIAAC (2012). Sample of respondents of 16-55 years of age. The figure shows the percentage of individuals of the sample performing at least once a month a basic numeracy, literacy or ICT task according to their country and level of education. Basic numeracy tasks are elaborate budgets, use calculator, use fractions, read diagrams and bills. Basic literacy tasks are read emails, guides, manuals and articles and write emails and reports. Basic ICT tasks are using email, internet and processing texts and conducting transactions. The classification is based following Principal Component Analysis on Table 7. b Percentage of individuals performing advanced tasks by country and level of education. Source: PIAAC (2012). Sample of respondents of 16-55 years of age. The figure shows the percentage of individuals of the sample performing at least once a month a advanced numeracy, literacy or ICT task according to their country and level of education. Advanced numeracy tasks are elaborate charts and using algebra. Advanced literacy tasks are read academic journals, read books and write papers. Advanced ICT tasks are using spreadsheets, coding and programming, and discussing at internet. The classification is based following Principal Component Analysis on Table 7

the already mentioned PIAAC. ${ }^{32}$ We use thirteen countries that are present both in IALS and PIAAC: Belgium, Canada, Czech Republic, Denmark, Finland, Germany, Ireland, Italy, Netherlands, Norway, Sweden, United Kingdom and the United States. The rescaled version of IALS has been designed so that measures of literacy cognitive skills (the only ones available in IALS) are comparable to those in subsequent assessments (in particular, ALL and PIAAC). All measures are in a $0-500$ scale.

IALS also asks to respondents who have been employed for the last twelve months about how frequently they perform certain tasks in their jobs in a manner that is comparable to the questions posed in PIAAC. In particular, we use the following reading or writing-related tasks: reading letters or memos, reading reports, articles or manuals, writing letters and writing reports or articles. IALS also includes tasks that we classify as numerical, such as reading bills, reading diagrams or using math to compute costs or budgets.

We use individuals born between 1950 and 1969, as they would still be below 65 years of age eighteen years after the IALS assessment, once PIAAC is conducted. We aggregate observations in cells defined by 10-year birth cohorts, schooling level, ${ }^{33}$ gender and country. For shorthand, we assign the IALS and PIAAC measurements of the 1950-1959 cohort to 40 and 55, respectively. Abusing notation, we assign the ages to the 1960-1969 cohort to 25 years in PIAAC (the average would be 30) and 55 in IALS (the average age would be 47). In Figure 3 we document the heterogeneity in life-cycle profiles across cohorts that we exploit to identify the response of literacy scores to the use of reading skills. The sample contains 50 cells of about 150 individuals in each of them (on average). ${ }^{34}$

\footnotetext{
32 An alternative source of information would be the ALL sample, that measures cognitive skills between 2003 and 2007. Unfortunately, we found a limited number of countries with repeated measurements both in PIAAC and ALL (Australia, Canada, Italy, Norway, Netherlands, US). As the synthetic cohort sample requires an ample variation in countries, we opted for analyzing IALS and PIAAC.

33 The OECD has elaborated a classification of schooling levels that is comparable across assessments, which is the one we use for this part of the analysis.

34 To increase the degree of variation in the data, we aggregate the use of reading tasks taking into account the reported frequency of each of the tasks.
} 


\section{Results}

\subsection{Task specialization by occupation}

Figure 2 provides a visual test of the variation that identifies the parameter of interest $\alpha_{2}$ by showing the different task intensity of 2-digit occupations that employ loweducated individuals. We compute the (frequency unweighted) relative basic task specialization and the difference in test scores and plot one against the other. The
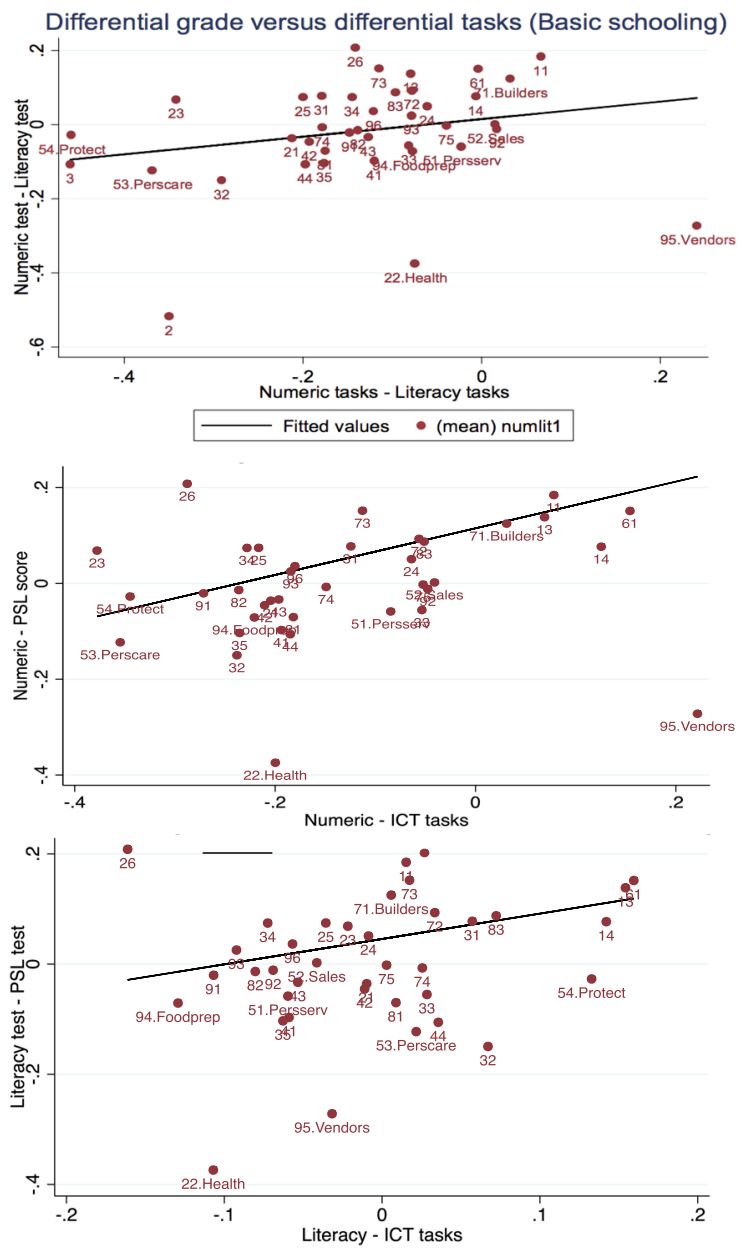

Fig. 2 Relative specialization in numeric tasks vs differential performance in the numeracy test. a Sample includes respondents in PIAAC database with basic schooling. b The differential grade between numeric test and literacy test is presented in the $\mathrm{Y}$ axis, while the $\mathrm{X}$ axis presents the difference between the proportion of numeric tasks done at least once a month over all numeric tasks considered and the proportion of literacy tasks done at least once a month over the all reading tasks considered. $\mathbf{c}$ Each dot is the average task intensity within each two-digit occupation and across all countries in the sample. $\mathbf{d}$ The OLS slope of the fitted line in the numeracy-literacy plot is .26 and the standard error is .17. The $\mathrm{R}$-squared is $20 \%$ 
relationship is positive: workers with compulsory schooling working in occupations specialized in math-oriented tasks perform relatively better in the numeracy test than in the literacy one. ${ }^{35}$

Consider two cases. The first are personal care workers (occupation number 53), who constitute $9 \%$ of all individuals with basic schooling in the full sample. Workers in that occupation are comparatively specialized in reading tasks, as the frequencyadjusted difference between their numerical vs reading tasks is negative. The tasks conducted by the average person in the occupation give clues about the rationale for that ranking. Personal care workers elaborate budgets, read diagrams or use calculators with an intensity that is half the sample mean (i.e. the corresponding entry under each of those numeracy tasks is well below 1 in Table 7). Conversely, personal care workers read guides or emails and write emails more frequently than the average worker does (i.e. the frequency of those literacy tasks is well beyond 1 in Table 7). In that sense, personal care workers are specialized in reading tasks. On the other part, sales workers (occupation number 52), account for $7 \%$ of all individuals with basic schooling in the full sample. Those workers specialize in numerical tasks. Namely, the frequency-adjusted difference between intensity in numerical and reading tasks is generally beyond 1 in Table 7 (i.e., they devote more of their time to numerical tasks than to reading ones).

\subsection{Regression analysis}

Table 2 implements a version of Model (3) on a pooled sample of the 15 countries conducting the three assessments (columns 1-9) and on the full sample (columns 10-12). The numeracy, literacy and problem-solving scores are normalized by the country-specific standard deviation. The first set of regressions uses a sample of workers with at most 10 years of potential working experience, the second set uses workers with more than 10 years of working experience and finally the full sample of workers (between 16 and 55 years of age). Table 2 does not distinguish between simple and advanced tasks. All models control for a quadratic polynomial of the number of years of potential working experience, two indicators of the educational level of the respondent (high school and college), the interaction between education and years of working experience, and age dummies (grouped in 5 year bands). We also include nine 1-digit occupation dummies, 22 industry dummies and country dummies. In addition, we include intercepts for female, foreign born, whether the respondent lives with his or her couple, whether he or she does not work, whether the exam was done in paper, two dummies with self-assessed health status and two intercepts denoting if the respondent enjoys learning new things -the latter to control for the possible influence of non-cognitive skills. ${ }^{36}$

We start with the sample of workers with a potentially shorter labor market history. The coefficient of $n-l$ in the first row, first column of Table 2 is 0.16 , implying that, relative to workers whose jobs have a similar incidence of numeric and

\footnotetext{
35 Examples of the main tasks conducted on-the-job are also provided in the appendix of the working paper version (see Martínez-Matute and Villanueva (2020).

36 All models estimated using the 10 imputed grades in PIAAC, and standard errors are adjusted by that multiple imputation.
} 


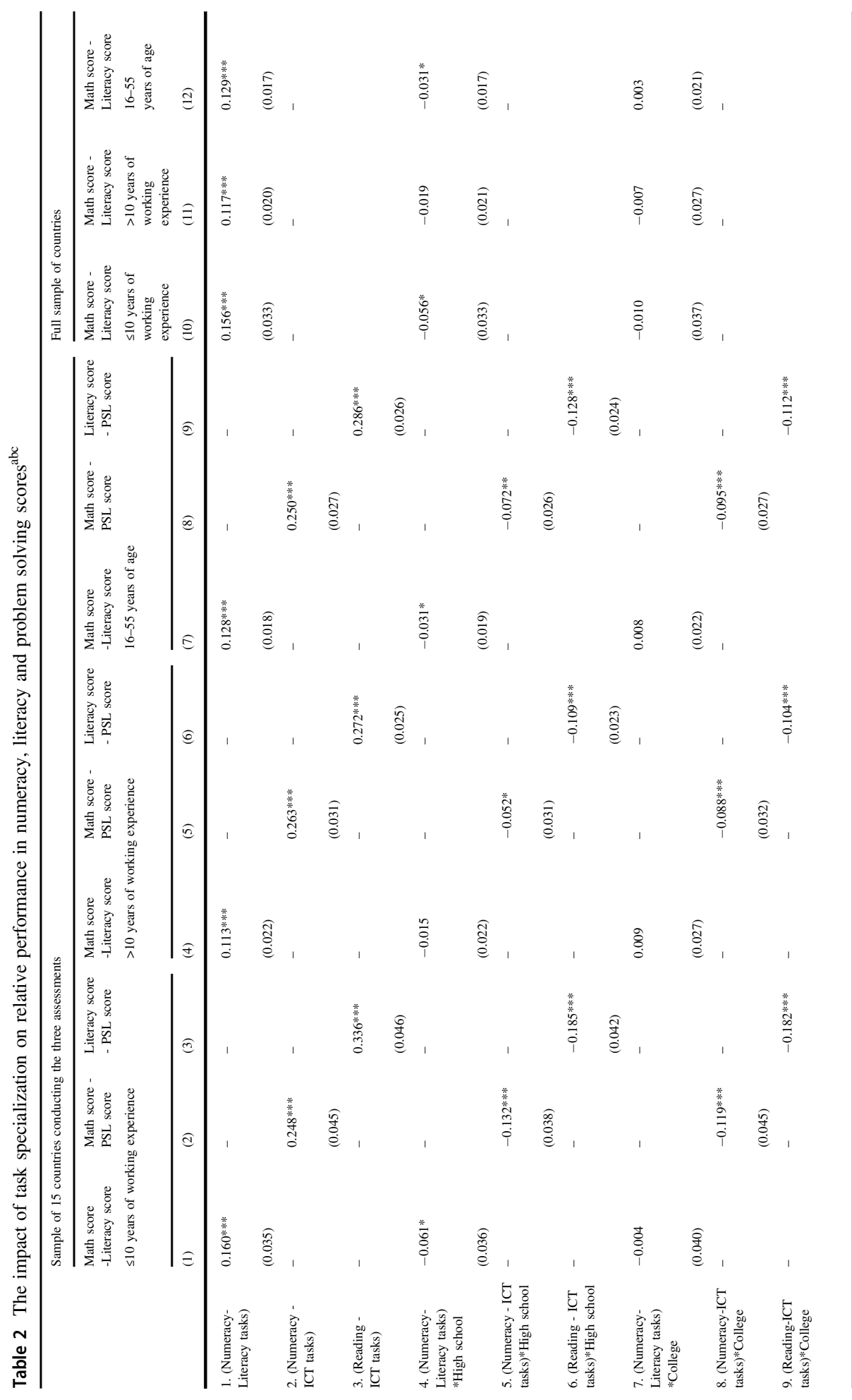




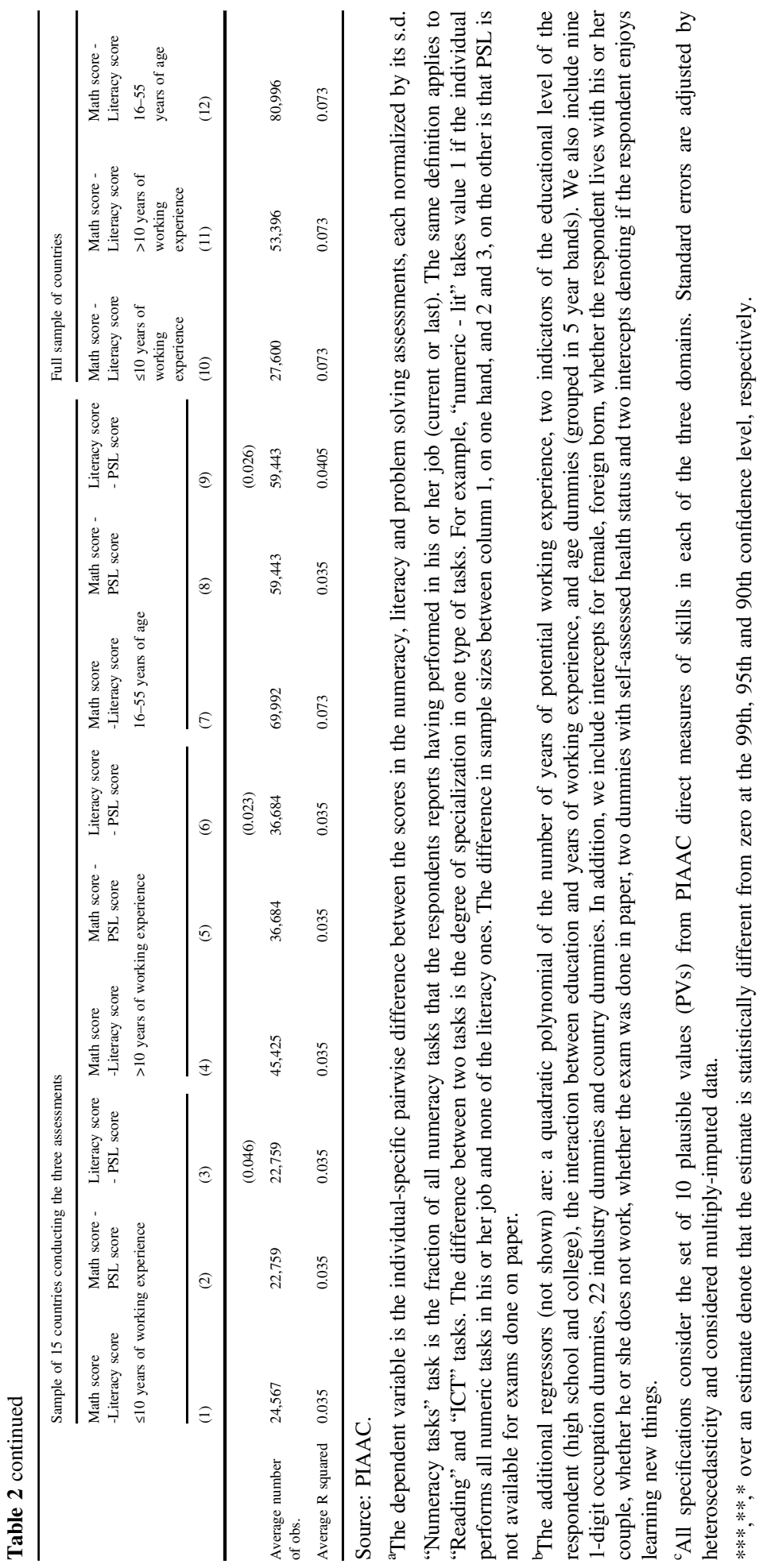


literacy tasks, workers with basic schooling in jobs that fully specialize in numerical tasks perform $16 \%$ of one standard deviation better in the numeracy test than in the literacy one. The impact of full specialization in numeric tasks among workers with a high school degree is obtained by adding the estimate in column 1 row 5 of Table 2 to that in column 1 , row 1 , and amounts to $9.9 \%=(0.16-0.061)$ of one standard deviation -about $60 \%$ of the return for workers with basic schooling.

When we measure the relationship between ICT specialization and problem solving skills, the results for workers with a basic schooling degree are qualitatively similar. Relative to workers in jobs with a similar share of numeric and ICT tasks, those who fully specialize in numeric tasks obtain $24.8 \%$ of one standard deviation higher score in the numeracy test than in the problem-solving one -see column 2, row 2 of Table 2. Finally, basic schooling workers in jobs intensive in reading tasks (and no ICT tasks) obtain in the literacy assessment an score $33.6 \%$ of one standard deviation higher than in the problem solving assessment -see column 3, row 3 of Table 2.

In sum, the estimates across columns 1, 2 and 3 (rows 1, 2 and 3, respectively) suggest that specialization in one type of tasks (say, numeric) increases scores in the skill domain related to that type of tasks relative to the other two.

A second result to note is that task specialization results in lower differences in the relative score among workers with either a high school or a college degree. For example, among workers with a high school degree, those who fully specialize in numeric tasks (as opposed to ICT ones) obtain a score in the numeracy assessment that is $11.6 \%$ of one standard deviation higher than that in the problem solving one ( 0.116 is the difference between the 0.248 estimate in Table 2 , row 2 , column 2 and the 0.132 estimate in Table 2, row 6 , column 2). The estimate is half that estimated among workers with basic education $(0.248 \%$ of one standard deviation).

Heterogeneity by potential experience. We compare the previous results to those in the sample of respondents with more than 10 years of working experience in 2012. The rationale is that on-the-job learning and investments are typically more productive in the earlier stages of the working life. The link between specialization in numerical tasks and the relative score in the numerical test is larger for workers at the beginning of the working experience life with basic schooling: full specialization in numeracy tasks (as opposed to reading ones) increases the relative numeracy score by $16.0 \%$ of one standard deviation for workers with at most 10 years of work experience (Table 2, column 1, row 1) and $11.3 \%$ of one standard deviation in the sample for more than 10 years of working experience (Table 2, column 5, row 1). However, the differences across assessments numeracy relative to problem solving and literacy vs problem solving do not vary much with potential experience. ${ }^{37}$

Table 3 conducts various sensitivity analyses of the results in Table 2. Firstly, we consider the possibility that workers may have qualifications above those required by their job. The second robustness check examines if the link between task specialization and cognitive skills is higher among workers in more stable jobs, who presumably have been doing the reported tasks for a longer period. The third robustness

\footnotetext{
37 Although not the topic of this study, the numeracy vs literacy results suggest that the possible skill deterioration documented in previous papers could be explained by differences in the type of numeric vs reading tasks conducted on the job over the life cycle.
} 


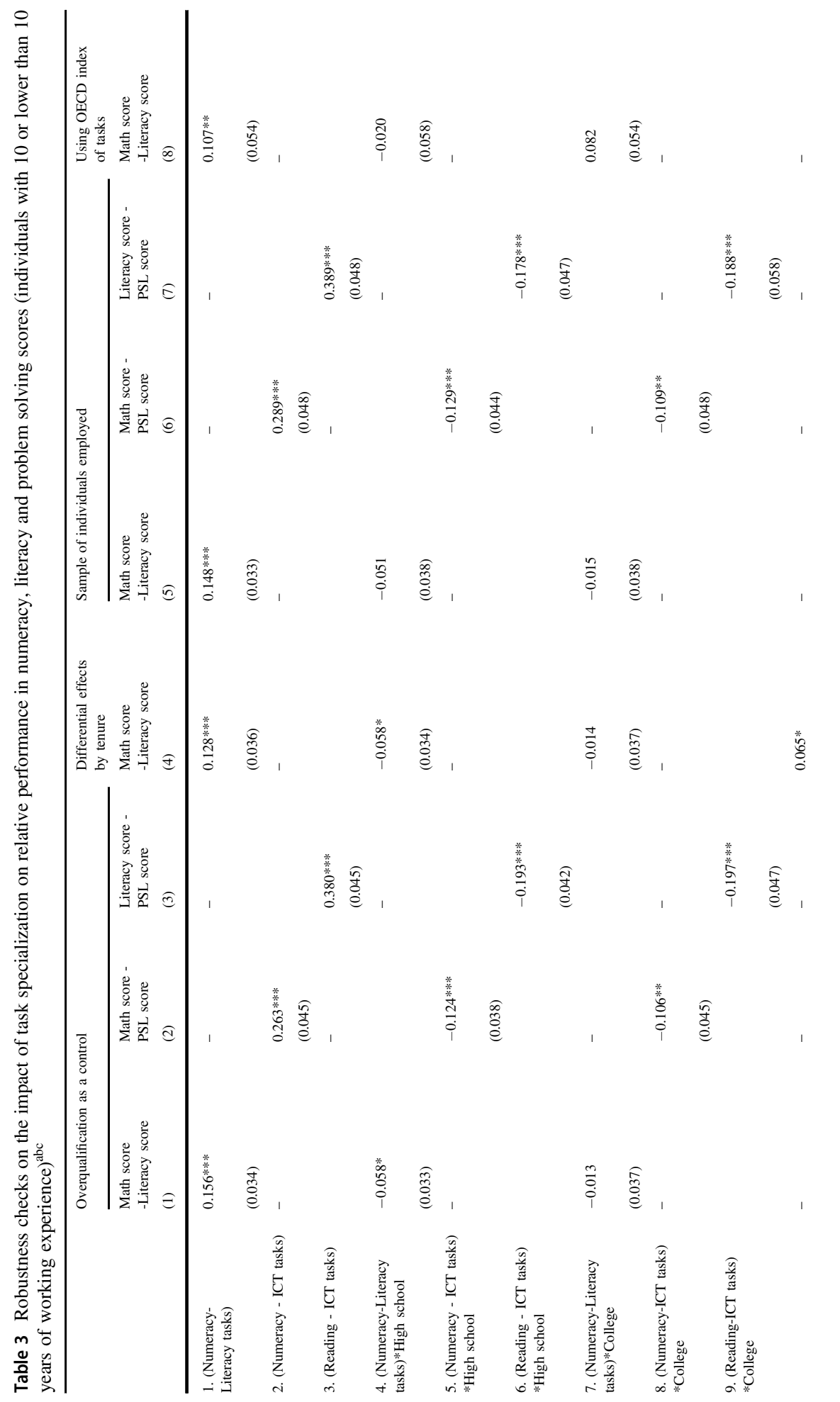

를 Springer 


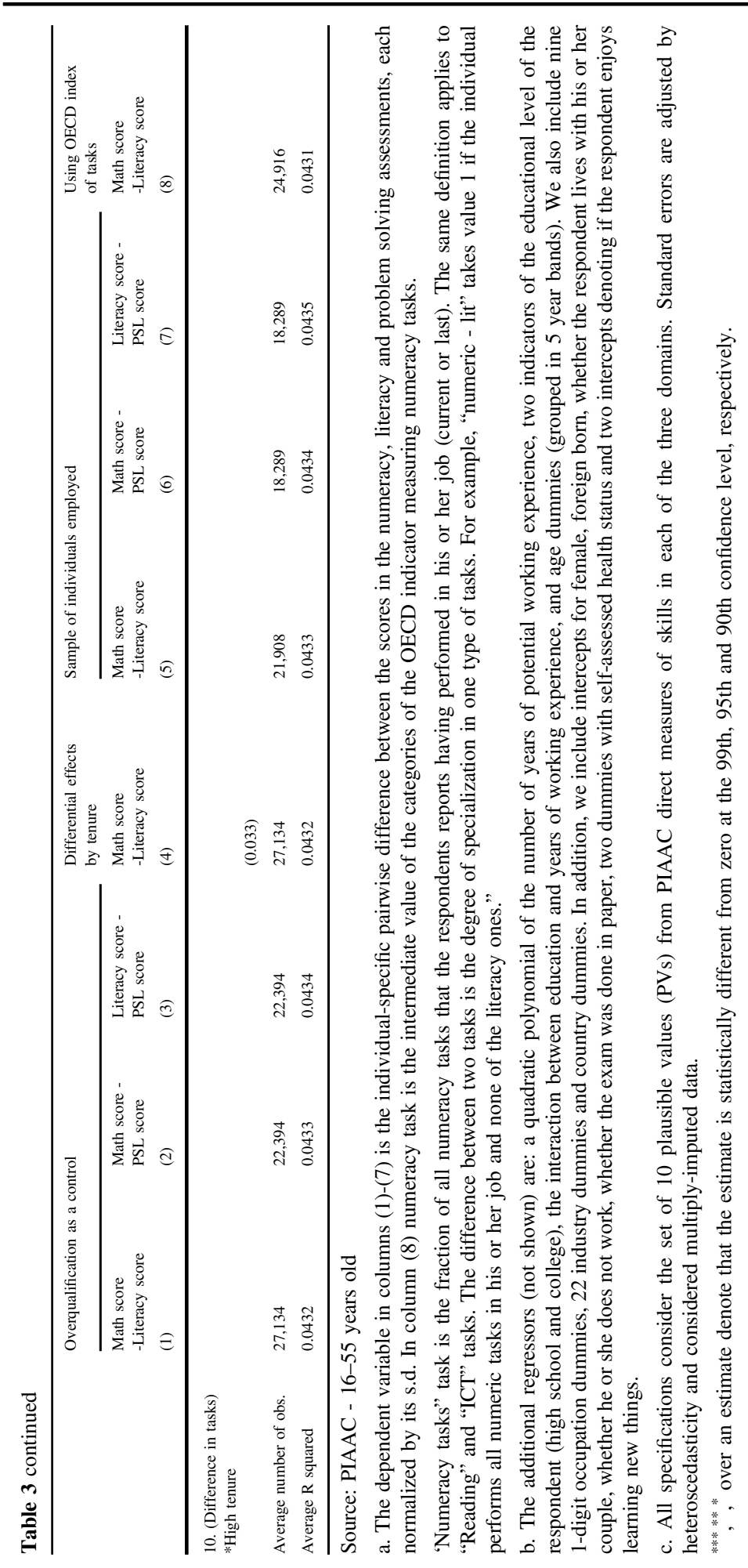


check excludes the unemployed at the time of the survey to test whether skill deterioration during non-employment periods affects the results. The fourth robustness check uses the alternative OECD index of task intensity.

While controlling for overqualification or considering samples of only individuals employed does not substantially vary the results, it is worth noting that the link between specialization in numerical tasks and a better performance in the numeracy test is stronger among low-skilled workers with tenures above the mean (the estimate is $12.8 \%$ of one standard deviation for workers with shorter tenures and $19.3 \%$ among those with longer ones). That finding is consistent with the notion that more time practicing a task increases cognitive skills more. However, tenure varies across workers in ways that depend on their unobserved ability, so other interpretations are possible.

\subsection{Simple vs advanced tasks}

As mentioned above, low-skilled workers conduct mainly simple tasks, so those are likely to drive the relationship with cognitive skills. Furthermore, under our assumptions, for workers with higher levels of schooling, the link may be informative about the degree of sorting in the labor market.

The differential skill return to specialization in basic tasks. Table 4 introduces individual fixed-effects to examine the relation between specialization in a set of basic tasks on the job and differential cognitive skills related to that domain. The results imply that respondents without either a high school or a college degree who fully specialize in basic numerical tasks score $10.5 \%$ of one standard deviation higher in the numeracy assessment than workers who are equally specialized in numeric and reading tasks (first column, first row). When we measure the impact of specialization in numeracy vs ICT tasks on numeracy scores (relative to problemsolving), the impact is somewhat smaller: $2.8 \%$ of one standard deviation, but it is imprecisely estimated. Finally, workers with basic schooling who specialize in reading vs ICT tasks obtain a higher score in the reading score than in the problem solving score ( $9.8 \%$ of one standard deviation, close to the $10.5 \%$ estimate in column 1 , row 1). The estimate of the impact of specialization in basic tasks on relative scores varies then between 2.8 and $10.5 \%$ among workers with primary schooling, but taking into account standard errors, we cannot reject the hypothesis that the three estimates presented in Table 4 are equal in size. This similarity of coefficients among pairs of skills serves as a check of the implicit assumption that the impact of numeric tasks on numeracy is similar to the impact of literacy tasks on literacy (see Lavy (2015), or Martínez-Matute and Villanueva (2020), for a discussion).

To gain precision, column 4 in Table 4 stacks all the previous regressions. That is, each individual contributes up to three observations: one for each pair of assessments. The coefficient of each pair of tasks on their correspondent assessments are constrained to be the same, and standard errors are clustered at the individual level to take into account that observations from the same individual may be correlated. The coefficient in Table 4, column 4, row 4 is 0.108 . This suggests that low-skill workers in jobs that specialize in one domain of basic tasks (for example, reading vs ICT) obtain a $10.8 \%$ of one standard deviation higher score in the related assessment (for example, literacy) than in the rest (for example, problem solving). 
Table 4 The impact of task specialization on relative scores (10 or lower than 10 years of working

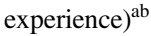

\begin{tabular}{|c|c|c|c|c|}
\hline \multirow{3}{*}{ Difference in normalized scores } & \multicolumn{4}{|c|}{ Sample of 15 countries conducting the three assessments } \\
\hline & $\begin{array}{l}\text { Numeracy- } \\
\text { Literacy }\end{array}$ & Numeracy-PSL & Literacy-PSL & $\begin{array}{l}\text { Difference } \\
\text { in scores }\end{array}$ \\
\hline & (1) & (2) & (3) & (4) \\
\hline \multirow[t]{2}{*}{ 1. (Numeracy-Reading tasks)basic } & $0.105^{* *}$ & - & - & - \\
\hline & $(0.048)$ & & & \\
\hline \multirow[t]{2}{*}{ 2. (Numeracy-ICT tasks)basic } & - & 0.028 & - & - \\
\hline & & $(0.060)$ & & \\
\hline \multirow[t]{2}{*}{ 3. (Reading-ICT tasks)basic } & - & - & $0.098^{*}$ & - \\
\hline & & & $(0.057)$ & \\
\hline \multirow[t]{2}{*}{ 4. (Difference in tasks)basic } & - & - & - & $0.108 * * *$ \\
\hline & & & & $(0.036)$ \\
\hline \multirow{2}{*}{$\begin{array}{l}\text { 5. (Numeracy-Reading tasks) } \\
\text { basic*High school }\end{array}$} & -0.053 & - & - & - \\
\hline & $(0.053)$ & & & \\
\hline \multirow[t]{2}{*}{ 6. (Numeracy-ICT tasks)basic*High school } & - & 0.010 & - & - \\
\hline & & $(0.060)$ & & \\
\hline \multirow[t]{2}{*}{ 7. (Reading-ICT tasks)basic*High school } & - & - & -0.091 & - \\
\hline & & & $(0.063)$ & \\
\hline \multirow[t]{2}{*}{ 8.(Difference in tasks)basic*High school } & - & - & - & $-0.070 *$ \\
\hline & & & & $(0.038)$ \\
\hline \multirow[t]{2}{*}{ 9. (Numeracy-Literacy tasks)basic*College } & -0.030 & - & - & - \\
\hline & $(0.052)$ & & & \\
\hline \multirow[t]{2}{*}{ 10. (Numeracy-ICT tasks)basic*College } & - & -0.002 & - & - \\
\hline & & $(0.064)$ & & \\
\hline \multirow[t]{2}{*}{ 11. (Reading-ICT tasks)basic ${ }^{*}$ College } & - & - & $-0.103^{*}$ & - \\
\hline & & & $(0.064)$ & \\
\hline \multirow[t]{2}{*}{ 12. (Difference in tasks) basic*College } & - & - & - & $-0.078 * *$ \\
\hline & & & & $(0.038)$ \\
\hline \multirow[t]{2}{*}{ 13. (Numeracy-Reading tasks)advanced } & 0.006 & - & - & - \\
\hline & $(0.048)$ & & & \\
\hline \multirow[t]{2}{*}{ 14. (Numeracy-ICT tasks)advanced } & - & 0.054 & - & - \\
\hline & & $(0.076)$ & & \\
\hline \multirow[t]{2}{*}{ 15. (Reading-ICT tasks)advanced } & - & - & 0.098 & - \\
\hline & & & $(0.075)$ & \\
\hline \multirow[t]{2}{*}{ 16. (Difference in tasks)advanced } & - & - & - & $0.085^{* * *}$ \\
\hline & & & & $(0.025)$ \\
\hline \multirow{2}{*}{$\begin{array}{l}\text { 17. (Numeracy-Reading tasks) } \\
\text { advanced*High school }\end{array}$} & 0.016 & - & - & - \\
\hline & $(0.052)$ & & & \\
\hline \multirow{2}{*}{$\begin{array}{l}\text { 18. (Numeracy-ICT tasks) } \\
\text { advanced*High school }\end{array}$} & - & 0.021 & - & - \\
\hline & & $(0.080)$ & & \\
\hline \multirow{2}{*}{$\begin{array}{l}\text { 19. (Reading-ICT tasks) } \\
\text { advanced*High school }\end{array}$} & - & - & 0.019 & - \\
\hline & & & $(0.075)$ & \\
\hline \multirow{2}{*}{$\begin{array}{l}\text { 20.(Difference in tasks) } \\
\text { advanced*High school }\end{array}$} & & - & - & 0.011 \\
\hline & & & & $(0.027)$ \\
\hline
\end{tabular}


Table 4 continued

\begin{tabular}{|c|c|c|c|c|}
\hline \multirow{3}{*}{ Difference in normalized scores } & \multicolumn{4}{|c|}{ Sample of 15 countries conducting the three assessments } \\
\hline & $\begin{array}{l}\text { Numeracy- } \\
\text { Literacy }\end{array}$ & Numeracy-PSL & Literacy-PSL & $\begin{array}{l}\text { Difference } \\
\text { in scores }\end{array}$ \\
\hline & (1) & (2) & (3) & (4) \\
\hline \multirow{2}{*}{$\begin{array}{l}\text { 21. (Numeracy-Literacy tasks) } \\
\text { advanced*College }\end{array}$} & $0.090^{*}$ & - & - & - \\
\hline & $(0.049)$ & & & \\
\hline \multirow[t]{2}{*}{ 22. (Numeracy-ICT tasks)advanced*College } & - & 0.041 & - & - \\
\hline & & $(0.075)$ & & \\
\hline \multirow[t]{2}{*}{ 23. (Reading-ICT tasks)advanced*College } & - & - & 0.041 & - \\
\hline & & & $(0.072)$ & \\
\hline \multirow[t]{2}{*}{ 24. (Difference in tasks)advanced*College } & - & - & - & $0.056^{*}$ \\
\hline & & & & $(0.027)$ \\
\hline Average number of obs. & 24.567 & 22.394 & 22.394 & 70,135 \\
\hline Average $\mathrm{R}$ squared & 0.059 & 0.0485 & 0.0418 & 0.060 \\
\hline
\end{tabular}

Source: PIAAC, sample of those with the three assessments (i.e., the sample excludes Italy, France and Spain).

a. The dep variable is the individual-specific pairwise difference between scores in the numeracy, literacy and problem solving assessments, each normalized by its s.d.

"Basic numeracy tasks" task is the fraction of all basic numeracy tasks that the respondents reports having performed in his or her job (current or last). The same definition applies to "Basic Reading" and "Basic ICT" tasks (See Table 7). The difference between two tasks measures the degree of specialization in one type of tasks. For example, "basic numeric - basic lit" takes value 1 if the individual performs all numeric tasks in his or her job and none of the literacy ones. The difference in sample sizes between column 1, on one hand, and 2 and 3, on the other, is that PSL is not available for exams done on paper.

b. The additional regressors (not shown) are: an interaction a quadratic polynomial of the number of years of potential working experience, two indicators of the educational level of the respondent (high school and college), the interaction between education and years of working experience, and age dummies (grouped in 5 year bands). We also include nine 1-digit occupation dummies, 22 industry dummies and country dummies. In addition, we include intercepts for female, foreign born, whether the respondent lives with his or her couple, whether he or she does not work, whether the exam was done in paper, two dummies with self-assessed health status and two intercepts denoting if the respondent enjoys learning new things

***,**** over an estimate denote that the estimate is statistically different from zero at the 99th, 95 th and 90th confidence level, respectively. Sd.e. account for heteroscedasticity and, in column 4 , for arbitrary correlation within the observations of the same individual

Impacts by school level. Next, we compare the impact of conducting basic tasks on the job on groups with higher educational levels. In practice, we subtract the estimate for respondents with high school from that for respondents with basic school, yielding the impact of specialization in basic tasks on the relative performance in the corresponding test for respondents with high school. We do this exercise using the estimates in Table 4, and using the sample where respondents have had less time to sort (individuals with less than 10 years of working experience). The impact of basic tasks on cognitive skills is smaller for high school graduates than for workers with basic schooling. When we measure specialization in basic tasks using the three measures as a benchmark (fourth column of Table 4) the impact of among high school graduates is $3.8 \%(0.038=0.108-0.070)$, subtracting the estimate in row 8 , column 4 , from that in row 4 , column 4 , in Table 4 . 
Overall, although point estimates vary with the definition of specialization, Table 3 suggests that the cognitive skill returns to specializing in basic tasks for workers with either high school or college degree are between non-significant and $40 \%$ of those we find among respondents with basic schooling. The result is consistent with the notion that learning through basic tasks on the job increases the skills of respondents with basic schooling.

\subsection{Gender}

We analyze in Table 5 separate impacts by gender. ${ }^{38}$ To achieve precision, we proceed as in Table 4, column 4, and stack the three measures for each individual (the three pairwise differences between numeracy, literacy and problem solving scores) and regress them on the corresponding pairwise difference in the associated tasks. Interestingly, the patterns we detected in Table 4 are more pronounced for females than for males.

Firstly, among low-skill men, those who specialize in basic tasks obtain a relative score in that domain $7 \%$ of one standard deviation higher than low-skill males in jobs with an even distribution of tasks. The standard error is 5\% of one standard deviation, so the estimate is not significantly different from zero. The corresponding estimate for low-skill females is twice as large: $14.7 \%$ of one standard deviation (standard error: $4.8 \%$ ).

Table 5 The impact of task specialization on relative numeracy, literacy and problem solving, by gender

\begin{tabular}{|c|c|c|c|c|}
\hline \multirow[t]{2}{*}{ Difference in normalized scores } & \multicolumn{2}{|c|}{$\begin{array}{l}10 \text { or less years of } \\
\text { experience }\end{array}$} & \multicolumn{2}{|l|}{ Full sample } \\
\hline & Males & Females & Males & Females \\
\hline \multirow[t]{2}{*}{ (Difference in tasks)basic } & 0.072 & $0.147 * * *$ & $0.075 * * *$ & $0.090 * * *$ \\
\hline & $(0.052)$ & $(0.048)$ & $(0.029)$ & $(0.025)$ \\
\hline \multirow[t]{2}{*}{ (Difference in tasks)basic*High school } & -0.022 & $-0.118 * *$ & 0.012 & $-0.061 * *$ \\
\hline & $(0.057)$ & $(0.054)$ & $(0.032)$ & $(0.028)$ \\
\hline \multirow[t]{2}{*}{ (Difference in tasks)basic*College } & -0.035 & $-0.136^{* * *}$ & -0.035 & $-0.064 * *$ \\
\hline & $(0.058)$ & $(0.052)$ & $(0.035)$ & $(0.028)$ \\
\hline \multirow[t]{2}{*}{ (Difference in tasks)advanced } & 0.035 & $0.149 *$ & $0.064 * *$ & $0.082 * *$ \\
\hline & $(0.050)$ & $(0.077)$ & $(0.027)$ & $(0.038)$ \\
\hline \multirow{2}{*}{$\begin{array}{l}\text { (Difference in tasks) } \\
\text { advanced*High school }\end{array}$} & 0.0043 & -0.068 & 0.008 & 0.001 \\
\hline & $(0.054)$ & $(0.076)$ & $(0.030)$ & $(0.038)$ \\
\hline \multirow[t]{2}{*}{ (Difference in tasks)advanced $*$ College } & 0.086 & -0.013 & $0.067 * *$ & 0.053 \\
\hline & $(0.052)$ & $(0.076)$ & $(0.027)$ & $(0.038)$ \\
\hline Average number of obs. & 32,344 & 39,177 & 89,223 & 99,765 \\
\hline Average $\mathrm{R}$ squared & 0.060 & 0.060 & 0.059 & 0.059 \\
\hline
\end{tabular}

Source: PIAAC. Sample of 15 countries exclude SP, IT and FR. Single-group sample is referred to a sample with individuals of the same education level.

Estimations are only referred to basic, high-school or college individuals. Estimations are different by type of tasks and normalized scores. 
Secondly, and as it was the case in Table 4, the response of differential scores to the variation in specializing in basic tasks is stronger for low-skill females than for women with a high school or a college degree. Among females with a high school degree, those who work in jobs where they fully specialize in a basic task (say, numeric) obtain a score in that domain (numeracy) $2.9 \%$ higher than females in jobs with a balanced set of tasks. The estimate is five times smaller that of low skill females.

The finding that the relationship between task specialization and scores is stronger for low-skill females than for low-skill males suggests that all our results cannot be entirely driven by sorting. Men tend to accumulate more working experience in the labor market. Hence, they might be more exposed to selection.

\subsection{The magnitude of the estimates}

The estimates become larger when we focus on the low working experience sample. This sample is specially interesting as workers with 10 or less than 10 years of potential experience have had less time to select into jobs more akin to their characteristics. The raw estimate of full specialization on the relative performance in the numeracy test among basic schooling respondents is $10.8 \%$ of one standard deviation (fourth row of column 4 in Table 4). For respondents with a high school degree, the impact of specialization in basic tasks is $3.8 \%$ (obtained by subtracting the 0.07 differential impact among respondents with a high school degree in column 4 , row 8 , in Table 4 from the main impact of 10.8 in column 4, row 4). The return to specialization in basic tasks on their jobs for respondents with a college degree is $2.8 \%$ of one standard deviation (obtained by subtracting the 0.078 impact in column 4 , row 12, in Table 3 from the main impact of 10.8).

Hence, under the assumption that the return to specializing in basic tasks for respondents with a high school or college degree basically measures sorting, we can apply equation (4) obtaining that workers with basic schooling who fully specialize in a set of basic tasks on a job perform around a $7 \%$ of one standard deviation better on the assessment relative to a worker with a balanced set of tasks. The remaining $3.8 \%$ (i.e., the difference between $10.8 \%$ shown in Table 4 , row 4 , and $7 \%$ shown in Table 4, row 8) would measure sorting in the labor market. We conduct now some back of the envelope calculations comparing our estimates to existing work analyzing how cognitive skills vary with formal education.

We do not have information on all tasks performed in all jobs during the working history of a worker, so we cannot establish if workers conducted numerical or other tasks in their current job only or during their complete working lives. Hence, we make the assumption that workers conducted numerical or literacy tasks during 4.8 years of experience, i.e. the average number of years worked among respondents with less than 10 years of potential experience. That conservative assumption implies that one year of conducting basic numeric tasks increases numeracy skills by between $1.46 \%(=7 / 4.8)$ and $2.25 \%(=10.8 / 4.8)$ of one standard deviation.

A caveat is that less than half of the workers with basic schooling conduct basic tasks (see Figure 1a). Assuming that $30 \%$ of workers with basic schooling conduct basic tasks on their jobs, the estimate of the impact of one year of experience on 
numeracy skills would be between $0.44 \%(=1.46 * 0.3)$ and $0.75 \%(=2.25 * 0.3)$ of one standard deviation.

To provide some sort of a benchmark, Hanushek et al. (2015) estimate that, in the United States, increasing compulsory education by one year increases skills by between $2.7 \%$ and $2.9 \%$ of one standard deviation. Hence, one extra year of schooling would be equivalent to between $1.3(=2.9 / 2.25)$ and 2 years $(=2.9 / 1.46)$ of on-the-job learning. If one takes into account that not all workers with basic schooling end up in a job involving basic tasks, one extra year of schooling would be equivalent to between $3.9(=2.9 / 0.75)$ and $5.2(=2.9 / 0.44)$ years of experience.

\subsection{Evidence from synthetic cohorts}

An alternative way of controlling for possible sorting in the labor market examines how cohort-level changes in the reading content of jobs relate to cohort level changes in literacy. As mentioned above, cohort-level changes in the reading content of a job are unlikely the result of individual sorting across jobs.

Figure 3 present cohort-level measures of the use of literacy tasks on the job in both assessments. This is shown for non-college workers in selected countries in the sample. The (frequency-adjusted) use of reading skills either increases to or stays constant around $40 \%$ between ages 25 and 40 (there are mild decreases in Canada and Finland). Between the ages 40 and 55, there is a great deal of heterogeneity, but typically the increase in the use of reading skills was milder between those ages than between 25 and 40 (see for example, Canada, Denmark, Sweden or Norway). We use that heterogeneity in life-cycle profiles across cohorts to identify the response of literacy scores to the use of reading skills.

The first row in Panel A of Table 6 shows that, among cohorts with basic education, an increase of $100 \%$ in the time devoted to reading tasks on the job increases scores in the literacy assessment by $80 \%$ of one standard deviation (standard error: $32 \%$ of one standard deviation). Once we account for the initial level of tasks performed on the job by the cohort in 1994, the estimate increases slightly to $83.4 \%$ of one standard deviation. Finally, controlling for the increase between 1994 and 2012 in the time devoted to math tasks the estimate stays stable at about $78 \%$ of one standard deviation (column 3). The latter result is reassuring, as it implies that it is precisely the increase in time devoted to reading tasks the factor behind the life-cycle increase in literacy tasks. The time devoted to numeracy tasks has little explanatory power.

On the other hand, it could be expected that the amount of time devoted to reading tasks in 1994 would explain cohort-level growth in literacy scores. The results do not support the view, as the coefficient is small and not statistically significant. A possible explanation is that reading tasks have increased substantially over the life cycle, diminishing the role of initial value.

The estimates in columns 2 and 3 of Table 6 imply that workers with primary schooling who increased their time to reading- or writing-related tasks on the job over the period increased their literacy scores by between $73 \%$ (Table 6, first row, column 3) and $83 \%$ of one standard deviation (Table 6 , first row, column 1). Dividing by 18 years of experience results in an estimate of $80 / 18=4 \%$ of one standard deviation per year. 
$\mathbf{a}$
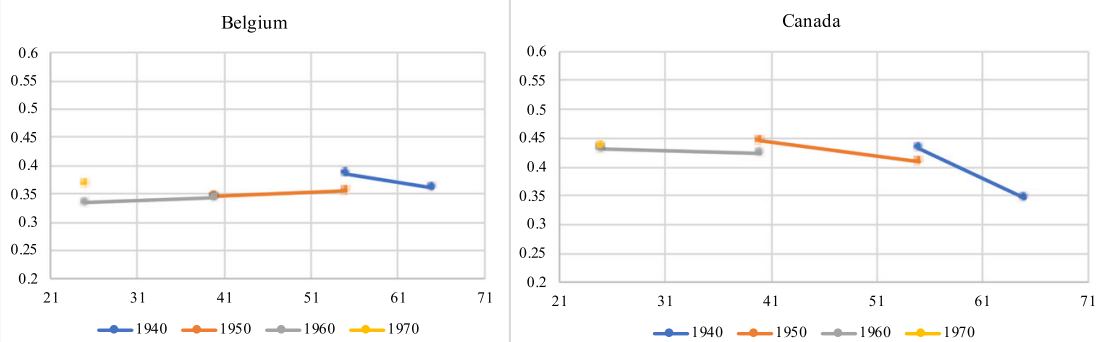

Denmark

Finland
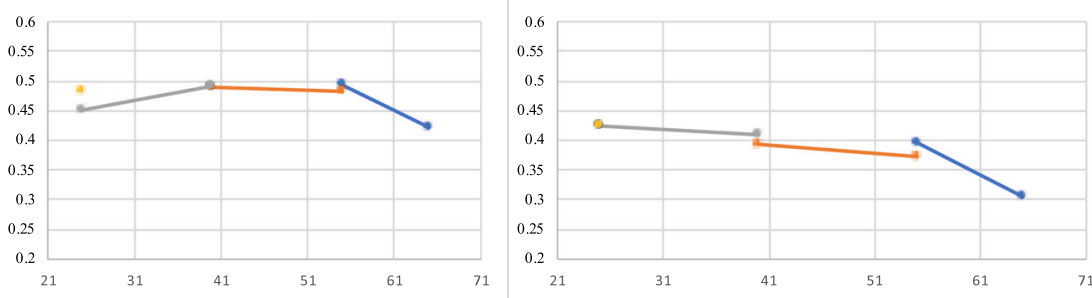

Ireland

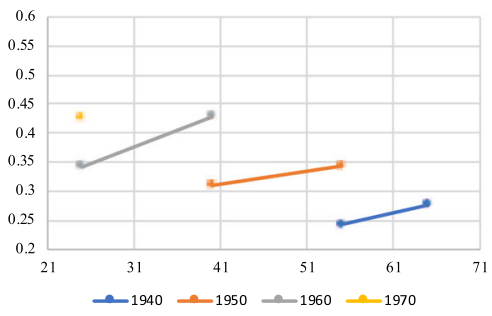

-1940 $1950 \sim 1960 \sim 1970$

Italy

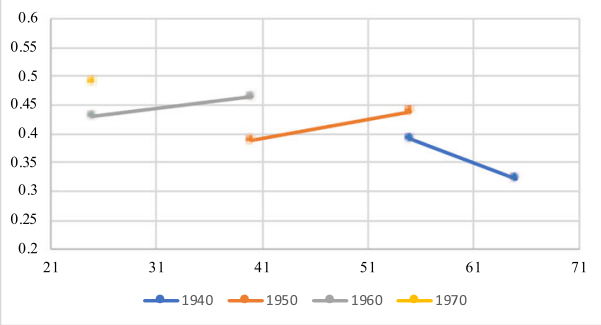

b
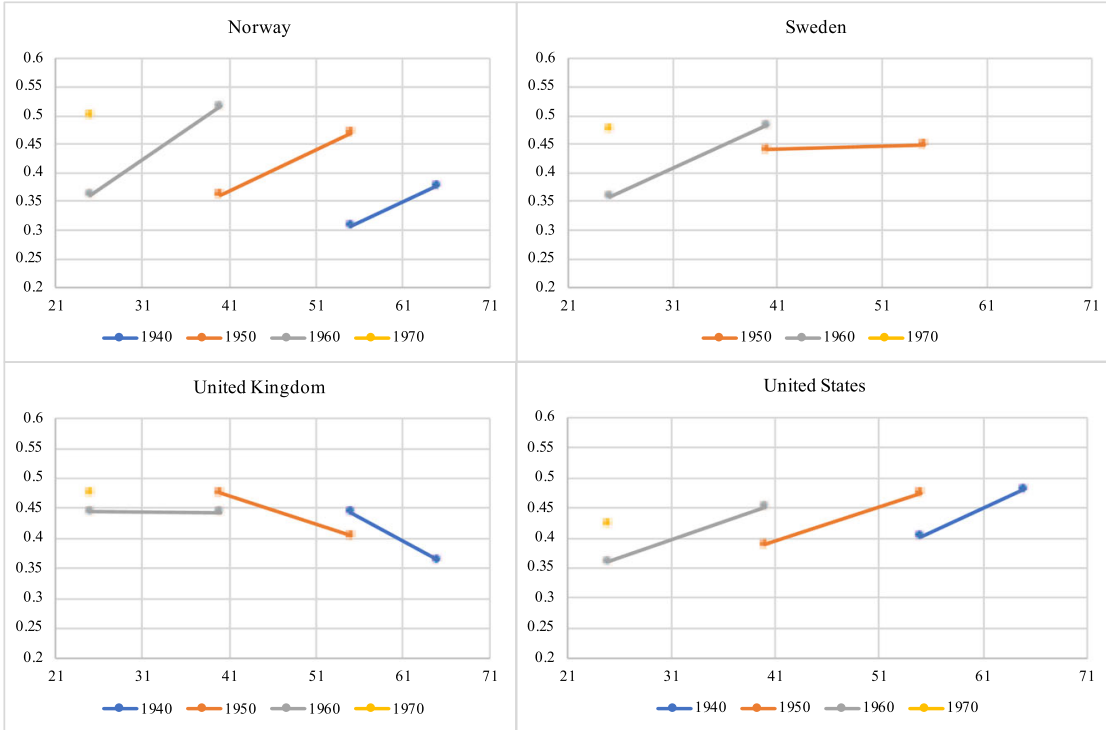

\section{睤 Springer}


Fig. 3 Fraction of time using reading tasks over the life cycle, evidence from IALS and PIAAC. Source: combined IALS (1994) and PIAAC (2012) samples of workers without a college degree. IALS asks respondents who worked in the last 12 months if they read letters or memos, reports, articles or manuals, wrote letters and reports or articles. We select a similar sample of individuals working in the last 12 months in PIAAC. The Figure includes cohorts born between 1940 and 1979, as they would still be below 65 years of age eighteen years at the time of the PIAAC assessment (2012). We aggregate observations in cells defined by 10-year birth cohorts,schooling level, gender and country. We assign the IALS and PIAAC measurements of the 1940-1947 cohort to 55 and 65, respectively (shown for completeness, not used in regresssions). We assign to the 1950-1959 cohort the ages of 40 and 55, respectively. We assign the ages to the 1960-1969 cohort to 25 years in PIAAC (the average would be 30) and 55 in IALS (the average age would be 47). The 1970-1979 cohort is available in PIAAC only

We can compare those estimates to those in the Table 4, row 4, column 4, that are about $10.8 \%$. The average actual experience of individuals with 10 years of experience at most is 4.8 years. Hence the fixed-effect estimate suggests about 2.25 $(=10.8 / 4.8)$ percent of one standard deviation per year. While estimates using synthetic cohorts are larger than those using worker-fixed effects is larger than the worker-fixed effect one, both estimates are not incompatible -specially if one takes into account that we do not know in PIAAC during how long were reading tasks acquired on the job.

Overall, the evidence from the synthetic cohort analysis is broadly consistent with the one found in PIAAC. We find this remarkable, given the very different set of assumptions involved in each procedure.

\section{Conclusions}

Cognitive skills account for a substantial share of the variation in labour market outcomes. This paper studies how on-the-job learning contributes to the acquisition of numeracy, literacy and problem-solving skills in eighteen OECD countries that implemented the PIAAC survey, focusing on individuals with low levels of schooling.

We use two empirical strategies. Firstly, we control for individual fixed effects by analyzing how the relative performance in numeracy, literacy and problem solving assessment vary with the differential exposure to numeracy, literacy and problemsolving tasks on-the-job. Our preferred estimates suggest that, among individuals with at most compulsory schooling, full specialization in basic numerical tasks increases the relative numeracy score by between $7 \%$ and $11 \%$ of one standard deviation. A second strategy uses repeated cross-sections of cognitive assessments to study how cohort-level changes in the reading content of jobs correlate with literacy scores. An interpretation of our results is that formal schooling and on-the-job learning are imperfect inputs in human capital production for workers with low levels of education.

Our findings have some implications for the design of active labour market policies. Firstly, cognitive test scores could be a good predictor of human capital that could indeed be easily checked for all unemployed. Secondly, specific tasks on-thejob might contribute to increase cognitive skills for low educated individuals. While the tentative rate of return to on-the-job training that we have estimated is between half and a fourth of that of formal schooling, the costs of increasing school 
Table 6 The impact of cohort-level changes in reading tasks on cohort-level changes in literacy scores

Dependent variable: (Literacy score PIAAC $2012-$ Literacy score IALS 1994)

Basic school sample

(1)

(2) $=(1)$

(3) $=(2)+$

+level 1994

numeric tasks

1. (Fraction of time in basic reading tasks

$0.806^{* * *}$

$0.835^{*}$

$0.781 *$

2012) - (Fraction of time basic reading tasks 1994)

(0.318) (0.429)

(0.420)

2. (Fraction of time basic numeric tasks 2012)

- (Fraction of time basic numeric tasks 1994)

- $\quad-$

3. Fraction of time basic numeric tasks 1994

$\begin{array}{ccc}- & 0.001 & 0.001 \\ & (0.001) & (0.001) \\ -0.274 * * * & -0.287 * & -0.308 * \\ (0.086) & (0.171) & (0.186) \\ 0.911 & 0.911 & 0.911 \\ & & \\ 0.149 & 0.025 & 0.093\end{array}$

4. (Fraction of time basic reading tasks 2012)

(0.404) (0.753)

5. (Fraction of time in basic numeric tasks 2012) - (Fraction of time in basic numeric tasks 1994)

6. Fraction of time basic numeric tasks 1994

$\begin{array}{ccc}- & -0.001 & -0.001 \\ & (0.001) & (0.001) \\ -0.359 * * * & -0.278 & -0.283 \\ (0.070) & (0.498) & (0.515)\end{array}$

\section{College sample}

7. (Fraction of time in basic reading tasks 2012) - (Fraction of time basic reading tasks 1994)

$0.198 \quad 0.899 \quad 0.736$

$\begin{array}{ccc}(0.326) & (0.620) & (0.870) \\ - & - & 0.195 \\ - & 0.001 & (0.596) \\ & & 0.001 \\ -0.239 * * * & -0.890 * & (0.001) \\ (0.058) & (0.511) & -0.894 \\ & & (0.519)\end{array}$

Source: Pooled IALS(1994) and PIAAC (2012) samples, cohorts born between 1960 and 1969 and 1950 and 1959. Specification (1) includes country dummies, dummies of the 1940-1950 cohort and an indicator of gender. The omitted country dummy is the US. Observations in each panel:50 cells $=(2$ cohorts $\mathrm{x} 2$ genders $\mathrm{x} 13$ countries) minus 2 cells with less than 10 cases. 
attendance for prime aged workers may be substantial. Thirdly, the amount of on-thejob learning is determined by jobs requirements, which vary greatly across sectors.

Compliance with ethical standards Conflict of interest The authors declare that they have no conflict of interest. Publisher's note Springer Nature remains neutral with regard to jurisdictional claims in published maps and institutional affiliations.

Acknowledgements A previous version of this paper was written with Aitor Lacuesta and Juan Francisco Jimeno as support material to the report of PIAAC study. We thank two anonymous referees that significantly contributed to enhance the paper, Luis Miguel Sanz, Francisco García Crespo and Ismael Sanz for their help with the database and, especially, Inge Kukla for her excellent assistance. We also thank Richard Desjardins, Jon Marius Vaag Iversen, Marcel Jansen and participants of the Workshop of Education, Skills and Labor Market Outcomes in Trondheim, EALE 2016 and 2017, ESPE 2016 and 2017, the 6th Lindau Meeting on Economic Sciences, SOLE 2018, TU Dresden, SOFI and QMUL seminars and IAAE 2019 for very useful comments. The opinions and analysis in this study are those of the authors and, therefore, do not necessarily coincide with those of the Banco de España or the Eurosystem.

Funding Open Access funding provided thanks to the CRUE-CSIC agreement with Springer Nature.

\section{Compliance with ethical standards}

Conflict of interest The authors declare no competing interests.

Publisher's note Springer Nature remains neutral with regard to jurisdictional claims in published maps and institutional affiliations.

Open Access This article is licensed under a Creative Commons Attribution 4.0 International License, which permits use, sharing, adaptation, distribution and reproduction in any medium or format, as long as you give appropriate credit to the original author(s) and the source, provide a link to the Creative Commons license, and indicate if changes were made. The images or other third party material in this article are included in the article's Creative Commons license, unless indicated otherwise in a credit line to the material. If material is not included in the article's Creative Commons license and your intended use is not permitted by statutory regulation or exceeds the permitted use, you will need to obtain permission directly from the copyright holder. To view a copy of this license, visit http://creativecommons.org/licenses/by/4.0/.

\section{Appendix}

Table 7 


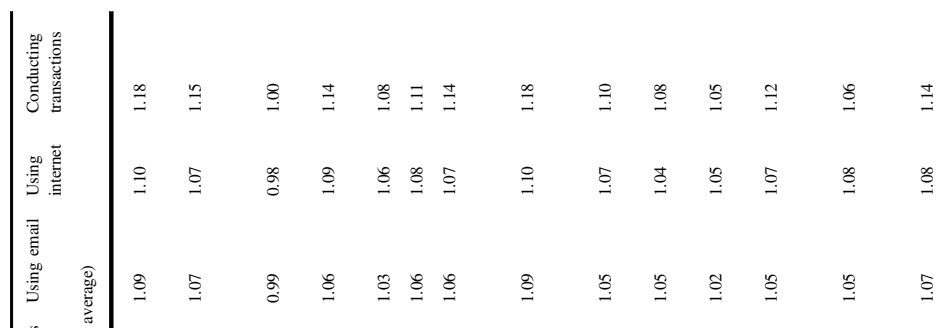

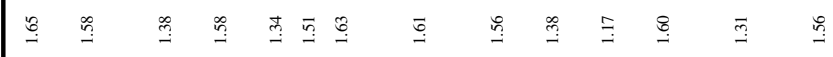

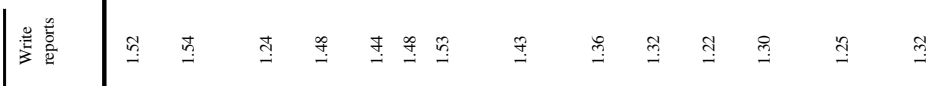

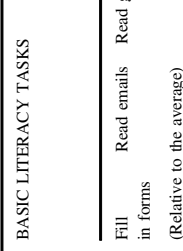

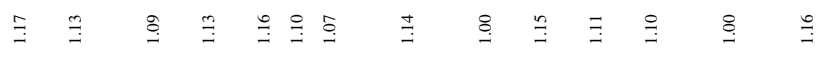

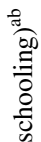

๕ ฮิ ฐ

ฐ

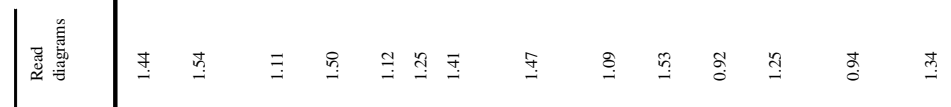

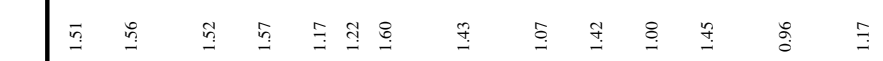

.

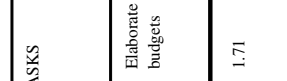

๑.

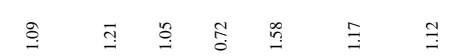

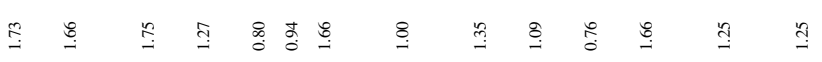

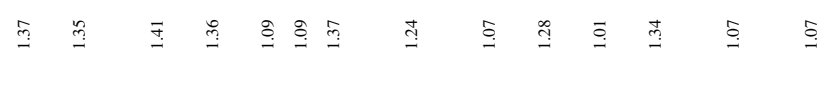




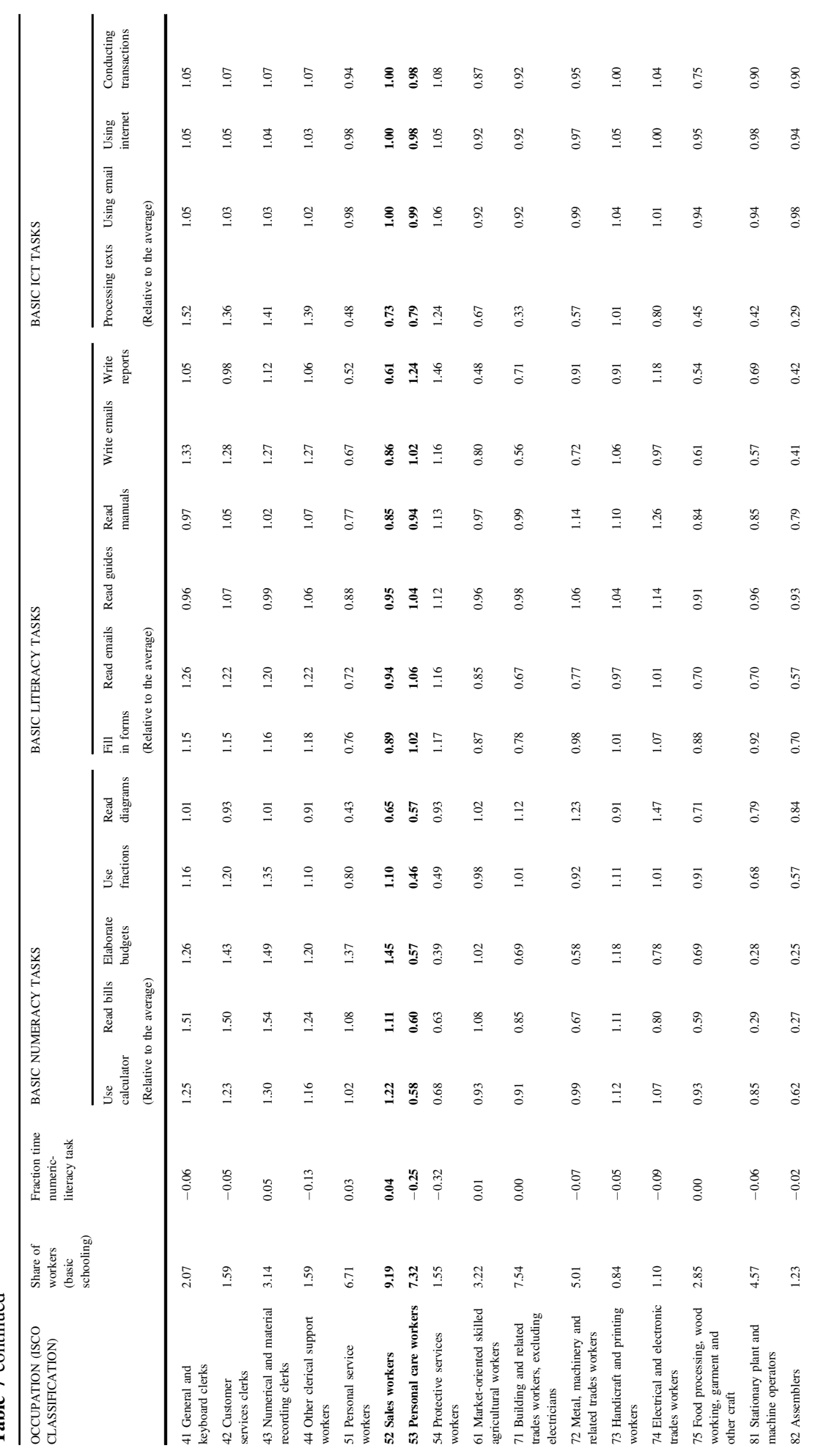




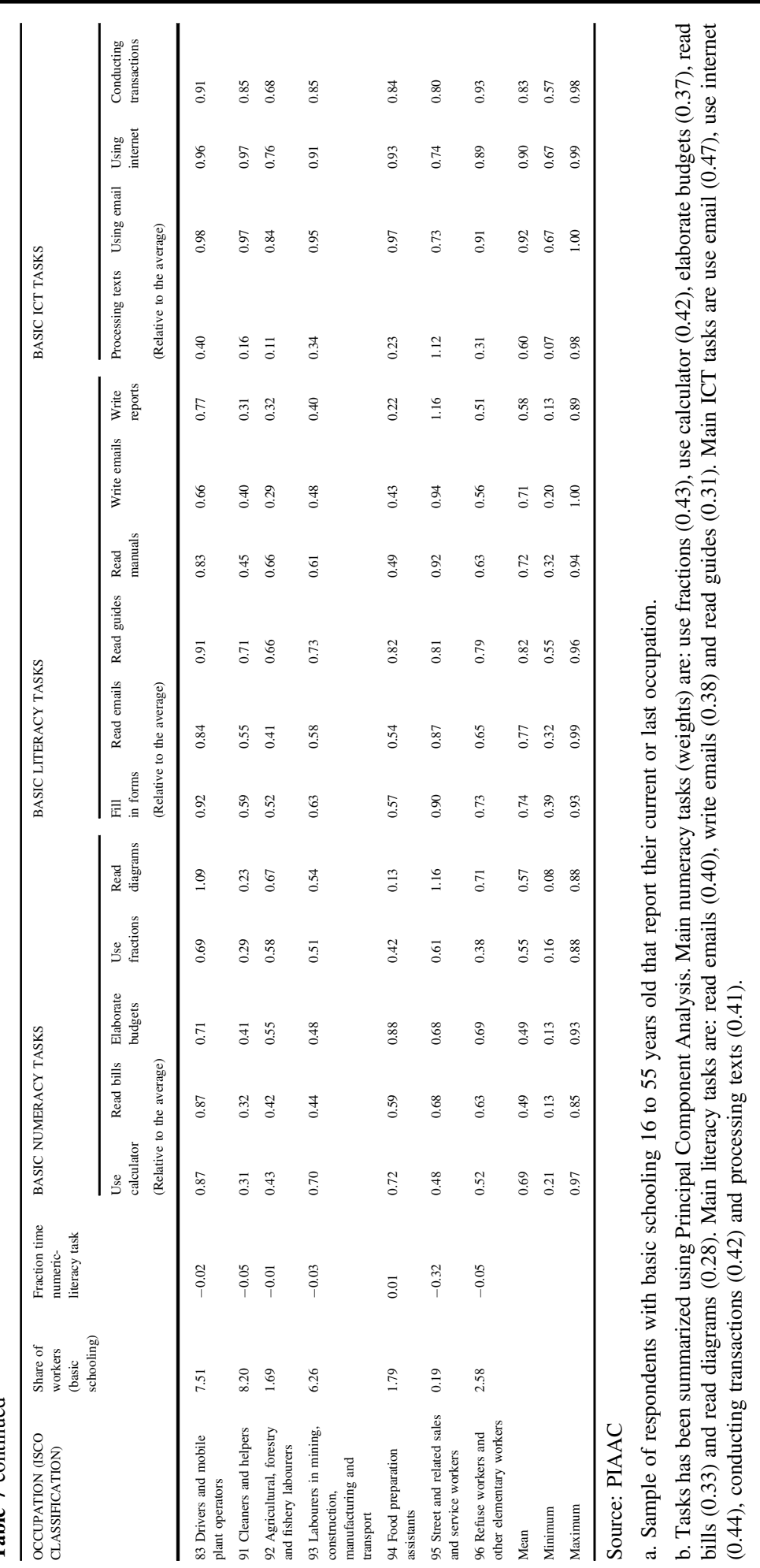




\section{References}

Angrist, J., \& Krueger, A. (1991). Does Compulsory Schooling Attendance Affect Schooling and Earnings. Quarterly Journal of Economics, 106(4), 979-1014.

Arellano-Bover, J. (2020). "The Effect of Labor Market Conditions at Entry on Workers' Long-Term Skills". The Review of Economics and Statistics, 2020, 1-45.

Barrett, G., and Riddell W. (2016). Ageing and Literacy Skills, OECD Education Working Paper no.145.

BenPorath, Y. (1967). The Production of Human Capital and the Life Cycle of Earnings. Journal of Political Economy, 75(4), 352-365.

Bietenbeck, J. (2014).“Teaching Practices and Cognitive Skills”. Labour Economics, 30, 143-153.

Blau, F. D. \& Kahn, L. M. (1996). "International differences in male wage inequality: institutions versus market forces”. Journal of Political Economy, 104, 791-837.

Card, D. (1999). The Causal Effect of Education on Earnings, in Orley Ashenfelter and David Card. Handbook of Labor Economics, 3, 1801-1863.

Carneiro, P., Heckman, J., \& Vytlacil, E. (2011). Estimating marginal returns to education. American Economic Review, 101(6), 2754-81.

Charles, J., Hurst, E., \& Notowidigdo, M. (2016). The masking of declining manufacturing employment by the housing bubble. Journal of Economic Perspectives, 30(2), 179-200.

Cunha, F., \& Heckman, J. (2007). The technology of skill formation. American Economic Review, 97(2), 31-47.

De la Rica, S., \& Rebollo, Y. (2019). "From gender gaps in skills to gender gaps in wages: evidence from the PIAAC", ISEAK, working paper 2019/3.

Edin, P., \& Gustavsson, M. (2008). Time out of work and skill depreciation. Industrial and Labor Relations Review, 61(2), 163-180.

Green, D., \& Riddell, C. (2013). “Ageing and Literacy Skills: A Comparison between Canada, Norway and the United States". Labour Economics, 22, 16-29.

Hanushek, E., Schwerdt, G., Wiederhold, S., \& Woessman, L. (2015). Returns to Skills around the World: Evidence from PIAAC. European Economic Review, 73(C), 103-130.

Jacobson, L., LaLonde, R. J., \& Sullivan, D. G. (1993). 'Earnings Losses of Displaced Workers'. American Economic Review, 83(4), 685-709.

Jeong, H., Yong, K., \& Manovskii, I. (2015). The Price of Experience. American Economic Review, 105 (2), 784-815.

Lagakos, D., Moll, B., Porzio, T., Qian, N. \& Schoellman, T. (2018). "Life-Cycle Wage Growth Across Countries". Journal of Political Economy, 126, 797-849.

Lavy, V. (2015). 'Do Differences in Schools' Instruction Time Explain International Achievement Gaps? Evidence from Developed and Developing Countries,. Economic Journal, 125(Nov. 588), 397-424.

Lazear, E. (2009). "Firm Specific Human Capital: A Skill Weights Approach". Journal of Political Economy, 117(5), 914-940.

Leuven, E., Oosterbeek, H., \& van Ophem, H. (2004). Explaining International Differences in Male Skill Wage Differentials by Differences in Demand and Supply of Skill. Economic Journal, 114, 466-486.

Lise, J., \& Postel-Vinay, F. (2020). Multidimensional Skills, Sorting, and Human Capital Accumulation. American Economic Review, 110(8), 2328-76.

Martínez-Matute., M. \& Villanueva E. (2020). Task Specialization and Cognitive Skills: Evidence from PIAAC and IALS, IZA DP No. 13555.

Metzler, J., \& Woessmann, L. (2012). The impact of teacher subject knowledge on student achievement: Evidence from within-teacher within-student variation. Journal of Development Economics, 99(2), 486-496.

Mincer, J. (1974): Schooling, Experience, and Earnings. Columbia University Press.

OECD (2013). "OECD skills outlook 2013: First results from the survey of adult skills", Paris: Organization for Economic Cooperation and Development.

Pető, R., \& Reizer, B. (2021). Gender Differences in the Skill Content of Jobs. Journal of Population Economics, 34, 825-864.

Rosen, S. (1972). Learning by Experience as Joint Production. The Quarterly Journal of Economics, 86(3), 366-382.

Roy, A. D. (1951). "Some Thoughts on the Distribution of Earnings". Oxford Economic Papers, 3, 135-146.

Silva, O. V., Lavy, V., \& Weinhardt, W. (2012). The Good, The Bad and The Average: Evidence on Ability Peer Effects in Schools. Journal of Labor Economics, 30(2), 367-414.

Villanueva, E. (2007). 'Estimating Compensating Wage Differentials Using Voluntary Job Changes: Evidence from Germany'. Industrial and Labor Relations Review, 60(4), 544-561. 